\title{
Engenharia Didática: implicações para a pesquisa no âmbito do ensino em Análise Complexa - AC
}

Didatical Engineering: some implications for the research the teaching Complex Analysis - CA

\section{Francisco Regis Vieira Alves}

Departamento de Matemática, Instituto Federal de Educação, Ciência e Tecnologia do Estado do Ceará - IFCE, Coordenador do Programa de Pós-graduação em Ensino de Ciências e Matemática - PGECM, Fortaleza, Brasil

fregis@ifce.edu.br

\begin{abstract}
Resumo
O presente artigo aborda e descreve as duas fases iniciais previstas por um design de investigação nominado de Engenharia Didática - ED. Dessa forma, tendo em vista um interesse declarado pelo ensino de Análise Complexa - AC, o trabalho enfatiza os elementos que detêm o potencial de consubstanciar as duas etapas iniciais de uma ED, nominadas por análises preliminares e análise a priori, com ênfase na descrição e concepção de apenas duas situações-problema. Assim, tendo em vista a extensa tradição da vertente francesa de pesquisa em Didática da Matemática, elege ainda a Teoria das Situações Didáticas - TSD, em caráter de complementaridade, afim de assegurar o possível controle da mediação didática, bem como o caráter preditivo de um aparato teórico-conceitual para a pesquisa, estruturado para o ensino de AC, reprodutível e replicável numa eventual situação empírica de aplicação no locus acadêmico.
\end{abstract}

Palavras-chave: Engenharia Didática, Ensino de Análise Complexa, Pesquisa, Tecnologia, Visualização.

\begin{abstract}
This article discusses and describes the two initial phases provided by a nominated research design of Didactical Engineering $-D E$. Thus, in view of an interest declared by the teachhing of Complex Analysis - $C A$, the work emphasizes the elements that hold the potential to constitute the two initial stages of an DE, nomitaded by preliminary and a priori analysis, with emphasis on description and conception of only two problems situations. So, in view of the long heritage of the French tradition in Didactics of Mathematics, also elects the Theory of Didactical Situations - TSD, in complementary character in other to ensure the reasonable control of the didactic mediation, as well as the predictive character of a theorical and conceptual framework for the research, structured for teaching of CA, reproductible and repeatable in any empirical situation of application in academic locus.
\end{abstract}

Keywords: Didatical Engineering, Teaching of Complex Analysis, Research, Technology, Visualization. 


\section{Introdução}

A vertente da pesquisa em Didática da Matemática, indubitavelmente, atingiu um patamar de solidificação e robustez do seu aparato técnico-teórico-conceptual, a partir de uma trajetória e tradição acadêmica visivelmente distinguida e que se sobressai desde os anos 80 .

Originada na França (DOUADY, 1995), divisamos um grande período de efervescência científica entre as décadas de 80 e 90. E, de modo simplificado, podemos apontar duas motivações que concorreram para a mobilização e a sinergia entre vários especialistas franceses, a saber: a necessidade de melhor conhecimento do aprendiz em situação-didática envolvendo os conhecimentos científicos matemáticos; um melhor conhecimento das relações entre ensino e aprendizagem em Matemática.

Assim, de modo inconteste, depreendemos que tal vertente, proporcionou a gênese de quadros de referência teórica a partir de um campo epistêmico intimamente próximo ao da Matemática. Adquiriu sistematização e ganho conceitual, a ponto de proporcionar um retorno ao saber matemático, contextualizado e localizado, além de permitir um entendimento das interações entre sujeitos epistêmicos (professor, alunos), um meio (milieau), bem como um conhecimento determinado/situado, em muitos casos, de modo institucional.

Por outro lado, diante de um extenso repertório de implicações para a pesquisa, no presente escrito, restringir-nos-emos ao problema da modelização teórica de situaçõesdidáticas tendo em vista o ensino e a aprendizagem de alguns conceitos científicos no locus acadêmico. Em outras palavras, no presente escrito, nos deteremos às potencialidades teóricas (ALVES, 2014a) de uso da Engenharia Didática - ED, tendo em vista a modelização e replicação de duas situações didáticas, no âmbito do ensino e a aprendizagem de certos conteúdos da Análise Complexa - (AC).

$\mathrm{O}$ interesse expresso na temática que declaramos no parágrafo anterior se justifica, na medida em que, embora reconheçamos a sinergia de especialistas, de várias áreas do conhecimento, com o intuito de envidar esforços no sentido de superar ou, pelo menos, suavizar determinados entraves ao entendimento dos aprendizes. Por outro lado, registramos práticas acadêmicas indefectíveis, que tendem a priorizar o viés algorítmico abstracionista e estruturalista da Matemática, sobretudo, no ambiente acadêmico.

In primo impetu, na próxima seção, indicaremos alguns elementos que devem nos auxiliar na demarcação do campo de interesse da nossa proposta ED, bem como suas implicações para a investigação e entendimento de alguns fenômenos originados no ensino e na aprendizagem de conceitos científicos.

\section{A constituição de um campo de investigação}

Em sua constituição histórica, divisamos forte influência da perspectiva piagetiana, no sentido de objetivarmos situações de ensino e, nelas, desenvolver análise pormenorizada do sujeito em situação de aprendizagem. Dessa forma, vislumbramos um "melhor aperfeiçoamento conceptual que adquire proeminência na medida em que o sujeito age sobre o real" (ROBINET, 1983, p. 1).

O quadro de constituição epistêmica da vertente $\mathrm{ED}$ ou, atualmente designado como um design de investigação (ARTIGUE, 2009), apresentou um extenso repertório de influências, dentre elas, J. Piaget (1896 - 1980), consubstanciadas a partir da sinergia de equipes organizadas de pesquisadores na França, sobretudo nas décadas de 80 e 90 .

En passant, podemos mencionar ainda os trabalhos de G. Barchelard (1884 - 1962), originalmente perspectivados no âmbito da Física, não obstante, adaptados ao caso do conhecimento matemático (ROBINET, 1983, p. 4). De modo fundamental, a herança epistemológica barchelariana $^{1}$ proporciona considerar o erro como algo revelador de concepções espontâneas e/ou mal adaptadas dos aprendizes em situação de aprendizagem.

Em outros estudos, divisamos preocupações atinentes à apropriação, por parte de um grupo de estudantes, do saber matemático. Robinet (1983, p. 6) distingue que "vários especialistas do ensino fazem referência sobre a construção de um determinado conhecimento matemático,

\footnotetext{
1 Conforme Artigue (1989, p. 6), a noção de obstáculo foi introduzida por Gaston Barchelard, em 1938. Apenas em 1976, a perspectiva de Bachelard foi adaptada por Guy. Brousseau, para o caso do saber matemático.
} 
todavia, Brousseau (1986b, p 43) estipulou que, para uma sequência de situações didáticas, tenhamos "maior possibilidade de organizar, para os estudantes uma gênese artificial dos conceitos".

Laborde (1997, p. 99) acentua que "as duas primeiras teorias desenvolvidas na França em Didática da Matemática giraram em torno do binômio situação-sujeito". A autora assinala que seus fundamentos foram declarados nos trabalhos de Vegnaud (1991) e Brousseau (1986b). Não obstante, assumiremos nosso maior interesse pelo segundo autor, embora a adoção das duas teorias pode proporcionar uma visão/perspectiva de complementaridade e, consequentemente, melhor precisão na definição de um objeto de interesse investigativo.

Antes de prosseguirmos, cabe assinalar o pensamento de Brousseau (1986a, p. 67), quando explica que:

O conhecimento não é organizado como uma resposta adaptável, adequada, econômica e pessoal em certas situações-problemas, ele é constituído de cultura de toda sorte, responsável em assegurar sua validade e, sua utilidade futura, não permite ao estudante outra alternativa, senão à alternativa de aderir ao mesmo.

Ora, depreendemos das considerações do autor que o sujeito não dispõe de uma resposta adequada, pronta e automática para um extenso repertório de situações de aprendizagem. Em muitos casos, tendo em vista o ambiente e os obstáculos, que determinam uma cultura matemática particular, o sujeito aprende se adaptando.

Margolinas (2004, p. 4) desenvolve comentários esclarecedores sobre a definição de um campo de investigação e no que diz respeito ao surgimento de um novo paradigma que evoluiu com a contribuição de vários trabalhos, observando ainda que:

Este paradigma surgiu da Matemática e, assim, nos interessam apenas os resultados envolvendo o contexto da Matemática, e não garantimos nenhuma passagem à outras disciplinas. (MARGOLINAS, 2004, p. 4).

De início, Margolinas (2004, p. 5) acentua certo tom de crítica ao mencionar que:
Todo mundo ou quase todo mundo parece saber e possuir algo a dizer sobre o ensino: os psicólogos, pois se trata de aprendizagem, os sociólogos, pois a escola é uma instituição social, os matemáticos, visto que, trata-se de aprender matemática. E os parentes, pois trata-se da educação de suas crianças.

O que se observa é que um discurso, embora fundamentado em seus campos epistêmicos precisos de formação original, não estão mais sob controle, quando tratamos em aplicá-los aos processos de transmissão/mediação de um saber científico, como no caso do saber matemático.

Num sentido contrário, no bojo das reflexões indicado por Margolinas (1995), se inserem os pressupostos da ED, posto que se enquadram como decorrência de evolução da pesquisa em Didática da Matemática, cujos fundamentos e pressupostos convergiram, tendo como escopo explicar fenômenos (ensino/aprendizagem) relacionados de modo intrínseco com o saber matemático.

De modo prosaico, podemos resumir uma ED, como uma sistemática de experimentação em sala de aula, por meio das seguintes etapas: análises preliminares, análise a priori, experimentação, análise a posteriori e, por fim, a validação. Laborde (1997, p. 103), por exemplo, descreve-as como: concepção, realização, observação e análise de uma sequência de ensino.

Ademais, a ED não se caracteriza apenas como uma inovação e, sim, "assume um estatuto de método, na medida em que sua concepção visa um conjunto de cenários possíveis de variáveis globais e locais dependentes". E, ainda, se mostra relevante "o valor pelo qual tais variáveis são fixadas pelo pesquisador em função dos efeitos esperados diante da conduta dos estudantes e a gestão da classe" (LABORDE, 1997, p. 104).

Laborde comenta que um dos aspectos importantes do método característico de uma ED, diz respeito à confrontação dos dados da análise a priori e a análise a posteriori e, acentuamos, que o termo a priori não referência uma posição temporal mas, sim, o gerenciamento de dados que ainda independem da experiência ou de uma realização local de uma sequência didática estruturada.

Laborde (1997, p. 104) indica três categorias de interesse em tais estudos produzidos, 
sobretudo, no final dos anos 80 para o início dos anos 90, a saber: a dimensão epistemológica, a dimensão cognitiva e a dimensão didática. A primeira dimensão adquire proeminência natural, tendo em vista que, a vigilância do pesquisador no que concerne aos conteúdos matemáticos de uma sequência de ensino e de que modo pode atuar/modificar sua transmissão.

A dimensão cognitiva é constatada por "alguns trabalhos que procedem uma análise fina das concepções preliminares dos aprendizes antes da aplicação de uma sequência", o que pode ocorrer de modo interno (ao cabo das primeiras situações relativamente às quais os estudantes são confrontados), ou de modo externo (a partir da comparação e apreciação de outras investigações que fornecem dados sobre concepções possíveis dos sujeitos).

Por fim, a dimensão didática é marcada por um interesse do expert pelos contratos didáticos (CHEVALLARD, 1991) locais instituídos em sala de aula, ou ao longo do tempo, adquirindo proeminência ao longo das explicações proferidas pelo pesquisador, tendo em vista suas escolhas de variáveis didáticas locais e globais.

Laborde (1997) chama atenção de algumas confusões recorrentes e que exigem maior atenção. Com efeito, a etapa de validação interna, originada no método da ED, se mostra condicionada na confrontação dos dados (confrontação e validação das hipóteses de trabalho) que a teoria supõe e prediz do ensino e da aprendizagem, com o dados empíricos.

Artigue (1996, p. 263) comenta que dados empíricos podem ser colhidos pelo uso de metodologias externas, isto é, obtidos por meio de: questionários, entrevistas individuais ou em grupos pequenos, que podem ser realizados a qualquer tempo do ensino ou ao final da sequência planejada pelos estudiosos.

$\mathrm{O}$ momento conseguinte, envolvendo a confrontação entre a análise $a$ priori e a posteriori se mostra delicado, uma vez que, Artigue (1996, p. 264) declara que "tal confrontação pode produzir distorções" e tem sido registrado na literatura especializada. Em alguns trabalhos, o pesquisador opta por realizar determinadas modificações na ED, todavia, conduzem a um distanciamento de uma real etapa de validação.

Os pressupostos de uma ED se mostram intimamente vinculados com um quadro de referências metodológicas. Nesse sentido, Artigue (1996, p. 265) comenta que:

A engenharia didática coloca problemas de natureza nova, pois, de um lado, a realização experimental supõe, ele mesma, uma espécie de transmissão em direção aos aprendizes, que devem ser os atores e, por outro lado, como quadro de metodologias externas, não podemos importar facilmente o 'sentido' de reprodução de outros campos científicos específicos.

E, pouco mais adiante, no contexto das discussões envolvendo preocupações em torno da reprodutibilidade de situações didáticas e sua obsolescência, com influência do pensamento de Brousseau, Artigue indica as seguintes hipóteses de reprodução no processo de modelização de situações: seu aperfeiçoamento, ao menos, local; a obsolescência das situações didáticas de ensino.

Laborde (1997, p. 105) evidencia um elemento imprescindível ao decurso de uma ED, quando analisa o relato de uma pesquisa que pode ser entendido como uma ação intencional em que:

O autor fornece ao leitor uma narração comentada do desenvolvimento, estruturado pelo tempo (cronologicamente) ou pelos temas escolhidos de análise. Em ambos os casos, o leitor se apropria das "lunetas" do autor, com exceção de passagens transcritas pelo autor da crônica, para um expediente de análise crítica.

E, sublinhamos, no bojo das preocupações do pesquisador com as respectivas produções do estudantes são previstas, num estudo, uma validação interna da sequência didática, bem como uma validação externa. A primeira envolve "uma descrição genérica da classe ou das condutas e tipos de produção majoritárias na classe, estudo de sua evolução e verificação de sua adequação no que concerne ao esperado dos estudantes" (LABORDE, 1997, p. 105).

Laborde (1997, p. 105) explica que a validação externa envolvendo uma comparação das produções dos estudantes antes ou ao longo da sequência, ou ainda após experimentação em sala, o que pode ocorrer por meio de entrevistas individuais ou em grupo, bem como por meio de questionários. E, também, por meio da comparação de produções externas, envolvendo outros alunos não submetidos à mesma sequência estruturada de ensino.

Apresentamos nossas considerações finais sobre as fases da ED, recordando que 
A fase de experimentação é o momento de se colocar em funcionamento todo o dispositivo construído, corrigindo-o quando as análises locais do desenvolvimento experimental identificam essa necessidade, o que implica um retorno à análise a priori, um processo de complementação" (ALMOULOUD, 2007, p. 177).

Ademais, tendo em vista a etapa subsequente, devemos permanecer atentos aos elementos de uma análise a posteriori, tendo em vista que a mesma consiste de "uma seção e o conjunto de resultados que se pode tirar da exploração dos dados recolhidos para a melhoria dos conhecimentos didáticos que se têm sobre as condições da transmissão do saber em jogo" (ALMOULOUD, 2007, p. 177). Não obstante, não ensejamos realizar todas as etapas de uma ED. Assim, restringir-nos-emos ao campo de discussão teórica para a proposição de uma ED.

Para concluir a presente seção, acentuaremos as considerações de Artigue (1996, p. 259), que se enquadram num momento de análise a priori e envolvem elementos de predição e controle de um campo de comportamento possíveis, bem como os comportamentos esperados dos estudantes. Para tanto, Artigue formula as seguintes questões: (i) qual o problema que cada aluno manifesta na solução de um problema? (ii) o problema pode ser explicitado em termos da teoria em jogo? (iii) que saberes são suficientes para que o aluno consiga compreender a tarefa? (iv) qual o controle possível do estudante na situação? (v) existem múltiplas fases na situação?

Certamente que as questões anteriores necessitam ser readaptadas, tendo em vista nosso objeto matemático de interesse. Não obstante, nosso âmbito de ação, do ponto de vista do corpus matemático analisado, leva em consideração um momento de transição ou passagem, no que concerne aos conceitos da Análise Complexa - AC.

Outras investigações têm acentuado dificuldades recorrentes no ensino e aprendizagem de conceitos científicos do Cálculo em uma variável que tendem a reaparecer no estudo, depois de algum tempo, do Cálculo em várias variáveis. Tal fenômeno adquiriu o nome de Transição Interna do Cálculo - TINC (ALVES, 2011; 2014a; 2014b; ALVES; BORGES NETO \& ALVES DIAS, 2012). Ademais, outro fenômeno de transição pode proporcionar e determinar a exigência de novas habilidades dos estudantes de Matemática, quando consideramos a transição da variável real para a variável complexa, chamada na literatura de Transição Complexa do Cálculo - TCC (ALVES, 2015a).

Vale recordar ainda uma tradição de estudos acadêmicos interessados no período de transição da escola para o contexto acadêmico (TALL, 1991; 1997; BALACHEFF \& GAUDIN, 2002) que assinalam um cenário de exigências e habilidades e formulações matemáticas inusitadas demandadas aos estudantes.

Todavia, nosso interesse se restringe ao ambiente acadêmico. Posto isso, no próximo segmento, descreveremos alguns elementos de ordem matemático-epistemológica e, com uma perspectiva de interesse na mediação didática, que não desconsidera os pressupostos da vertente da didática francesa, abordaremos algumas trajetórias teóricas de sua exploração em sala de aula, atribuindo maior ênfase nas análises preliminares e análise a priori de nossa proposta teórica.

\section{Sobre o ensino de Análise Complexa}

Como mencionamos na seção anterior, temos registrado trabalhos acadêmicos que relatam os entraves no contexto da transição do contexto de ensino escolar para o acadêmico. Por outro lado, em outras investigações, deparamos o interesse, ainda correlato ao problema da transição de estudos, todavia, no interior de um determinado corpus teórico (ALVES, 2011).

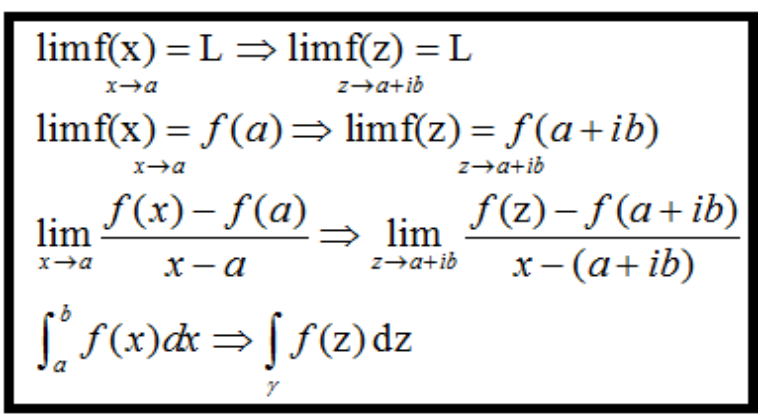

Figura 1 - Descrição das mudanças simbólicas num sistema particular de representação do Cálculo e sua transição para a variável complexa. Fonte: Elaboração do autor

De modo mais visível, a simbolização (BROUSSEAU, 1986, p. 67), que indicamos logo em seguida, poderá revelar, de imediato, as 
modificações e novas exigências conceituais e de cunho abstracionista, que passam a ser consideradas no recente universo de estudos dos alunos (ver figura 1 ).

Grosso modo, no bojo das considerações da Transição Complexa do Cálculo (- TCC), do ponto de vista das variáveis consideradas, mudamos da variável real para a variável complexa. Isto é, podemos indicar tal transição, simbolicamente, por $x=x+i 0 \stackrel{\text { transição }}{\Rightarrow} z=x+i y$.

Por outro lado, mudanças drásticas podem ser vislumbradas no que diz respeito ao viés topológico. Por exemplo, Needham constata que "a habilidade de $z$ correr de modo livre no plano desencadeia em nós um grau de liberdade visual que permaneceu dormente tão prolongadamente quando nos restringimos à análise dos números reais em seu comportamento numa prisão unidimensional." (NEEDHAM, 2000, p. 377).

Esse autor explora um expediente que busca enfatizar a visualização como componente catalizador de um entendimento tácito e inicial. De fato, Needham (2000, p. 66) se apoia em termos metafóricos para explicar a manifestação gráfico-geométrica de singularidades isoladas. Num caso específico, quando se refere à função racional $h(z)=\frac{1}{1+z^{2}}$, menciona que as manifestações das singularidades nos pontos $z= \pm i$ são visualmente percebidas, "pelo aparecimento de vulcões em erupção sobre os pontos" (ver figura 2).

As perspectivas de Needham (2000), Wegert (2012) e de Polya \& Latta (1979) se distinguem, na medida em que deparamos um ensino acadêmico do Cálculo e de Análise, que torna hegemônica a aplicação de práticas obsoletas e indefectíveis, que buscam enfatizar o caráter estruturante dos fundamentos da Análise, mas, que, na verdade, são consequência de um "erro pedagógico" (ÁVILA, 2002, p. 85), o qual, exige nossa vigilância.

No que concerne às considerações formuladas por Needham (2000), assinalamos as possibilidades de recurso à visualização, como componente capaz de impulsionar um entendimento tácito e inicial do aprendiz, todavia, estudos especializados (ALVES; BORGES NETO \& ALVES DIAS, 2012; ALVES \& BORGES NETO, 2012) indicam que o próprio sistema de representação simbólico de um ramo em Matemática, proporciona entraves/obstáculos ao entendimento gráficogeométrico, caso desconsideremos as possibilidades de exploração da tecnologia atual (ALVES, 2014b) no ensino universitário.

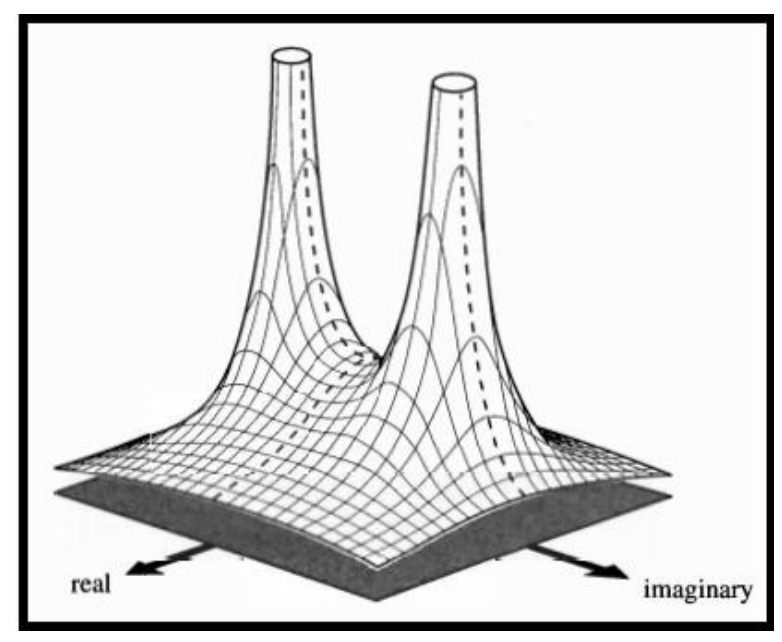

Figura 2 - Visualização de "vulcões" que designam um sentido/significado metafórico para a noção de singularidades de funções, na perspectiva de Needham (2000, p. 66)

Assim, diante dos elementos que carecem maior atenção, por parte dos pesquisadores, indicamos a seguinte problemática: tendo em vista o contexto do TCC, que proporciona uma série de novas exigências aos aprendizes, que elementos detêm a capacidade de evitar ou, pelo menos, suavizar, concepções indesejáveis na aprendizagem dos conceitos da AC?

Cabe distinguirmos concepções que consideramos desejáveis e outras que admitimos atuarem no sentido contrário de uma aprendizagem. Para tanto, nos apoiaremos nas categorias formuladas na tese de Alves (2011), nominadas por elementos de transição e elementos de ruptura. De modo prosaico, um elemento de transição que deparamos no Cálculo em uma variável real, poderá ser identificado ainda num contexto ulterior, de aprendizagem do Cálculo em várias variáveis, bem como, no contexto da AC. Certamente, em dependência de uma mediação didática planejada e eficaz do professor. Possivelmente, o exemplo clássico instado por Alves diz respeito à regra de L'Hospital. De fato, os estudantes dedicam um considerável tempo de estudo da referida regra, com o intuito de se livrarem de simbologias 
como: $+\infty-\infty, \frac{ \pm \infty}{ \pm \infty}, \frac{0}{0}, 0^{0}, \infty^{0}, 0 \cdot \infty, 0^{\infty}$, etc., conquanto que, quando consultamos os compêndios especializados de Cálculo em várias variáveis, registramos o seu desaparecimento (elemento de ruptura).

Pouco mais adiante, no contexto da $\mathrm{AC}$, os estudantes reencontram passados vários anos de estudos acadêmicos, a mesma regra que, em muitos casos, permite o estudante se livrar de limites, de modo automático, sem a necessidade de envolver um expediente maior de investigação, bastando aplicar, de modo automático, o processo de derivação das funções em jogo. Dessa forma, Alves (2011, p. 234) indica que a regra de L'Hospital constitui um elemento de ruptura. Por exemplo, os estudantes deparam que simbologias do tipo $\frac{ \pm \infty}{ \pm \infty}, \frac{0^{+}}{0^{-}}, \frac{0^{-}}{0^{+}}$que não adquirem mais sentido prático e matemático no contexto da AC (ALVES, 2014b). .

Mas, desde que adotamos uma perspectiva afetada pela ED, seguindo as etapas indicadas por Almouloud (2007, p. 172 - 173), elegemos as seguintes hipóteses de investigação: (a) tendo em vista um sistema representacional intrincado e complexo, os estudantes conseguem um entendimento visual de certas noções apenas com arrimo da tecnologia; (b) determinadas habilidades ou conhecimentos exigidos no âmbito da variável real tendem a ser empregadas ou, pelo menos, readaptadas no caso da variável complexa (atuam como elementos de transição); (c) determinadas propriedades válidas no âmbito da variável real podem ser invalidadas ou não tendem a se manifestar no caso da variável complexa (identificação de elementos de ruptura, e entraves à aprendizagem).

Não perseguiremos efetuar aqui sua constatação com base em dados empíricos. Todavia, na fase subsequente, identificaremos problemas de ensino e de aprendizagem vinculados aos conteúdos de AC. E, com base e amparo em tal sistemática, delinearemos questões da investigação, tendo como referências as hipóteses anteriores apontadas e que detêm a possibilidade de serem investigadas de modo empírico (confirmadas, refutadas, substituídas ou reformuladas).

Dois elementos devem ser evidenciados na etapa seguinte, de acordo com Almouloud (2007, p. 172), a saber: (i) estudo da organização matemática; (ii) análise didática do objeto matemático escolhido.

\section{Análises preliminares}

De modo standard, e como mencionamos nas seções anteriores, o componente do estudo epistemológico desempenha papel visceral, logo nas etapas iniciais de uma incursão investigativa com amparo na ED. Dessa forma, do ponto de vista evolutivo, assinalamos o processo de sistematização e elevado estágio estrutural alcançado pela noção de função (BOTTAZZINI \& GRAY, 2013; GRAY, 2015).

Bottazzini (1986, p. 7) assinala como recorrentemente indicado na literatura científica, o pensamento bourbakiano influenciou na descrição/formulação da noção de função por meio da linguagem conjuntista.

Bottazzini (1986, p. 9) comenta que:

O termo 'função' surgiu, pela primeira vez, num manuscrito de Leibniz, entre 1692 e 1694, porém, nesses anos de discussão acerca da noção de função e os símbolos empregados para sua representação (as características, na terminologia de Leibniz), surgem nas correspondências entre Leibniz e Johann Bernoulli I (1667 - 1748). Por exemplo, numa carta enviada em setembro de 1694, a integral $\int n d z$, como uma série formal infinita $n z=\frac{z^{2}}{2 !} \frac{d n}{d z}+\frac{z^{3}}{3 !} \frac{d^{2} n}{d z^{2}}-\ldots$ em que o termo ' $\mathrm{n}$ ' designa uma quantidade indeterminada.

Nos trabalhos de Euler, Bottazzini (1986, p. 12) constata que, na definição de função, a variável pode assumir qualquer valor, inclusive, os valores imaginários. Em 1770, Euler não forneceu uma definição formal para termos imaginários, todavia, desenvolveu com maestria, métodos para sua manipulação.

Bottazzini (1986, p. 12) explica que:

Variável complexa tem seu primeiro surgimento oficial num volume I, da obra de Euler, na introdução, em que Euler demonstra o teorema da fatorização polinomial em $C$, relatando sua decomposição em fatores lineares. 
Uma contribuição relevante envolveu sua formulação na definição da função (multivalor) logaritmo e exponencial complexa.

De fato, Bottazzini (1986, p. 12) comenta que “Euler definiu a função $\exp (z)$, para $z=x+i y \in C$ e a sua inversa $\log (z)$ que definiu logo depois, entretanto, para valores estritamente positivos". Mas, sua definição da exponencial complexa, permitiu a descrição das fórmulas celebradas e invariavelmente discutidas nos compêndios atuais (CECÍLIA \& BERNADEZ, 2008; PAP, 1999; SOARES, 2014; SHOKRANIAN, 2011), designadas por $\cos (z)=\frac{e^{i z}+e^{-i z}}{2}$ e $\operatorname{sen}(z)=\frac{e^{i z}-e^{-i z}}{2 i}, \operatorname{assim}$ como a forma complexa de $e^{i t}=\cos (t)+i \operatorname{sen}(t)$, para $\forall t \in I R$.

Desde que, nas situações subsequentes, desenvolveremos também nosso interesse pelo processo de integração complexa, recordamos os trabalhos precursores de Augustin Louis Cauchy (1789 - 1857). Com efeito, Ferguson (1958, p. 1) comenta que "em 1825, Cauchy estava hábil para estabelecer um teorema que, ao longo do tempo, demonstrou constituir o fundamento de inúmeras pesquisas na teoria da variável complexa."

Ferguson (1958, p. 1) enuncia o seguinte teorema: seja $f$ uma função analítica na variável $z$, definida numa região $R$ simplesmente conexa. Sendo a função e sua derivada contínuas numa região $R$ e tomando qualquer contorno fechado $\gamma$ na região, teremos $\int_{\gamma} f(z) d z=0$.

Ferguson assinala o caráter de impecável rigor dedicado por Cauchy na demonstração do fato anterior, todavia, bastante laborioso. Como consequências, outros resultados e formulações adquirem representatividade no edifício matemático, como os resultados extraídos por Bernhard Riemann (1826 - 1866), em 1851 e, também, por Édouard Goursat (1858 - 1936), em 1883. E, embora Cauchy forneceu os fundamentos, apenas Riemann produziu as condições necessárias e suficientes para a validez do teorema há pouco mencionado.

Daí, seguindo as consequências dos resultados de Riemann, os estudiosos do trabalho de Goursat estabelecem, em 1900, que o teorema de Cauchy é também válido, sem a hipótese da continuidade da função derivada.

Imediatamente, no âmbito da discussão dos matemáticos contemporâneos a Goursat, surgiu uma especulação sobre as possibilidades de recíproca do mesmo teorema. Assim, Giacinto Morera (1856 - 1909), em 1902, demonstrou o resultado que envolveu a recíproca do teorema anterior, com determinadas modificações das hipóteses, e envolve a produção das condições de analiticidade de uma função na variável complexa.

Fergunson (1958, p. 3) comenta que "o sucesso do teorema de Morera e de Goursat proporcionaram o direcionamento da atenção para o teorema de Riemann, desconsiderando a continuidade das derivadas parciais das funções $\left.u_{x}^{\prime}(\mathrm{x}, \mathrm{y}), \mathrm{u}_{y}^{\prime}(\mathrm{x}, \mathrm{y}), v_{x}^{\prime}(\mathrm{x}, \mathrm{y}), v_{y}^{\prime}(\mathrm{x}, \mathrm{y})\right)^{\prime}$. E, logo em seguida, os trabalhos de Paul Montel (1876 - 1975) foram devotados a busca do mesmo resultado, que não fora alcançado, até que, em 1923, H. Looman, forneceu parcial solução para o problema.

Fergunson (1958, p. 3) acrescenta que, "desde que a solução de Looman não se mostrou completa, os esforços de D. Menchoff, publicado em 1931, foram necessários diante das correções dos trabalhos de Looman".

Desse modo, o teorema resultante, parte devido a $\mathrm{H}$. Looman, e parte devido ao matemático Menchoff, recebeu atenção do matemático S. Sacks, que em 1933, ofereceu à comunidade científica a formulação do teorema que recebeu o nome de ambos os matemáticos, ou seja, o teorema de Looman-Menchoff (ARSOVE, 1954; GRAY \& MORRIS, 1978; SOARES, 2014).

Para concluir esta pequena digressão de ordem histórica, imprescindível nas análises prévias de uma ED (ALMOULOUD, 2007, p. 172), recordamos as explicações de Medvedev (1991, p. 22), ao mencionar que:

Embora pouco visíveis os resultados de topologia na teoria das funções na variável complexa, apenas com o estabelecimento das teorias das funções de variável real e a teoria dos conjuntos, do ponto de vista topológico, é que tais disciplinas adquiriram forma.

Ora, as indicações anteriores de Ferguson e Medvedev proporcionam um entendimento 
acerca da estrutura matemática evolutiva do conceito investigado (ALMOULOUD, 2007, p. 132).

Em nosso caso, optamos por restringirmos a atenção ao conceito de diferenciabilidade e a integração de funções na variável complexa. Assim, a indicação desses dois conceitos matemáticos (ou processos) matemáticos, tendo em vista a escassez de investigações empíricas (ALVES, 2014a; 2014c) sobre os dois assuntos e a natureza epistemológica reconhecidamente complexa, deverão direcionar nossas futuras reflexões didático-metodológicas possíveis, tendo em vista o seu ensino em sala na academia.

\section{Análise a priori e construção das situações-didáticas para o ensino de AC}

Para efeito de maior sistematização, assumiremos que uma situação-problema envolve "a escolha de questões abertas e/ou fechadas numa situação matematizada ou menos matematizada, vinculada a um campo de problemas colocados em um ou vários domínios de saber." (ALMOULOUD, 2007, p. 174).

Vale observar que, no campo de saberes referenciados por Almouloud (2007), é possível, tendo em vista o nível elementar da Matemática, considerar situações "menos matematizada". Entretanto, em nosso caso, o modelo matemático condiciona, fortemente, todas as estratégias e as ações e decisões dos aprendizes. Essa variável didática é prevista, de modo geral, por Brousseau (1986, p. 412).

Nas duas situações-problemas que abordaremos na presente seção, assumiremos os pressupostos e a sistemática prevista pela ED. Ademais, tendo em vista a consideração de uma perspectiva de influência de caráter metodológico, assinalaremos a dialética dos momentos de ação, formulação, validação (BROUSSEAU, 1986a) e a fase de institucionalização (ALMOULOUD, 2007, p. 23).

Situação-problema I: decidir o caráter de diferenciabilidade da seguinte função $f(z)=\frac{\phi^{z}-\cos (\pi z) \cdot \phi^{-z}}{\sqrt{5}}$, com $z=x+i y$ e $\phi=\frac{1+\sqrt{5}}{2}>0$. Em seguida, concluir se tal função é harmônica.

Comentários: na situação anterior assumiremos a importância da exploração da habilidade de visualização como componente preliminar e catalizador de um raciocínio tácito e inicial do aprendiz relacionado com a noção de diferenciabilidade da função $f(z)=\mathrm{u}(\mathrm{z})+\mathrm{iv}(\mathrm{z})$.

Situação de ação. Logo de início, quando lidamos com a função $f(z)$, a literatura especializada nos informa sobre as dificuldades para sua descrição analítica da seguinte forma $f(z)=\mathrm{f}(\mathrm{x}+\mathrm{iy})=\operatorname{Re}(f(x, y))+,i \cdot \operatorname{Im}(f(x, y))$, como mencionado por Alves (2015a).

Um entrave preliminar, quando os alunos buscarem descrever as partes imaginária e real da função da situação-problema I, reside na dificuldade em descrever a soma anterior. Sua vantagem reside no fato do tratamento a ser dispensado, por exemplo, às funções $\operatorname{Re}(f(x, y)$, e $\operatorname{Im}(f(x, y)$,$) descritas nas variáveis reais.$

Com efeito, lidamos com funções em duas variáveis reais e, nesse caso, com recurso ao CAS Maple, podemos proporcionar aos estudantes a visualização de suas superfícies correspondentes, definidas no espaço $I R^{3}$ (ver figura 3).

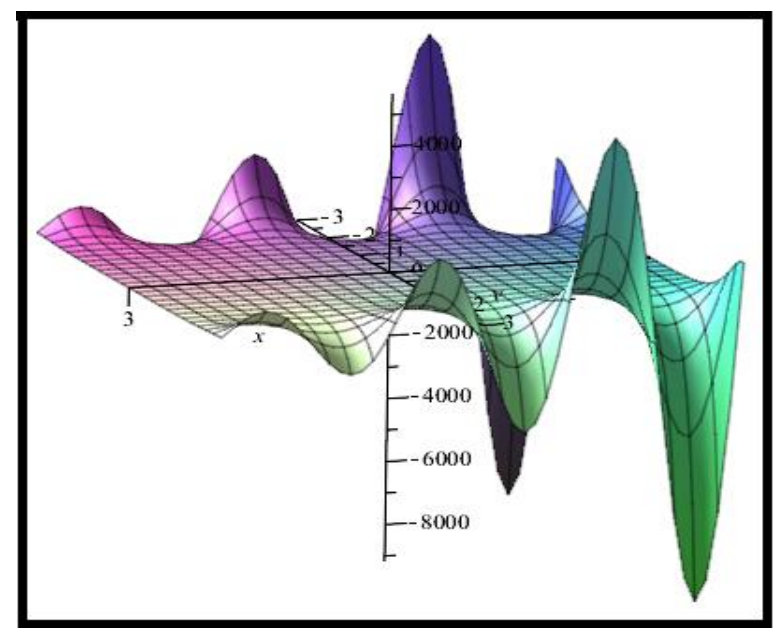

Figura 3 - Visualização/identificação da superfície no espaço, correspondente à parte real da função $\operatorname{Re} f(z)=\operatorname{Re}(\mathrm{f}(\mathrm{x}, \mathrm{y})) \quad$ com recurso ao CAS Maple

As relações e significados matemáticos devem ser depurados na etapa inicial, na medida em que, uma linguagem compreensível por todos deve ser mobilizada (ALMOULOUD, 2007, p. 
38), não obstante, nossa perspectiva de abordagem busca a descrição de um cenário que se apoia na visualização, tendo como escopo a produção das conjecturas preliminares e a possibilidade de produção de algum insight (ALVES, 2012).

Dessa forma, tendo a atenção direcionada ao que exibimos nas figuras 3 e 4, os alunos devem ser estimulados a readaptar e ressignificar seus conhecimentos à cerca do Cálculo em várias variáveis, na medida em que consideram funções nas variáveis reais ' $x$ ' $e^{\prime} y$ '.

Nas figuras 3 e 4, com auxílio do CAS Maple, o expert pode instigar os estudantes, no sentido de perceber, do ponto de vista da exploração visual e manipulação do modelo computacional, o comportamento de suavidade da função nas proximidades da origem. Por outro lado, lançando uma atenção e movimento perceptual que se distancia do ponto $(0,0,0) \in I R^{3}$, poderão divisar a existência de "morros" ou "cristas" elevadas da superfície.

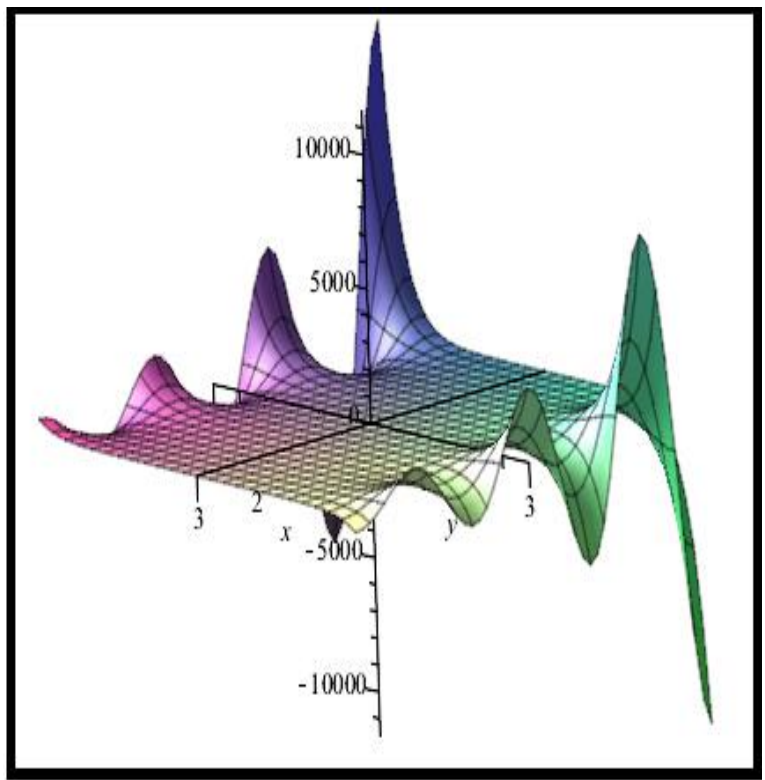

Figura 4 - Visualização/identificação da superfície correspondente à parte imaginária da função $\operatorname{Im} f(z)=\operatorname{Im}(\mathrm{f}(\mathrm{x}, \mathrm{y}))$ com recurso ao CAS Maple

Ora, Alves (2011) acentua uma significação metafórica e intuitiva de noções do Cálculo em várias variáveis e Análise Real (ALVES, 2013; LIMA, 2010), ensina que a existência de "vulcões", "cristas" ou "lombadas" sugerem, localmente, a perda do caráter de diferenciabilidade, posto que, a manutenção da referida propriedade sugere, do ponto de vista local, uma sensação de "suavidade".

$\mathrm{O}$ autor assinala que, em decorrência de uma mediação adequada, o papel desempenhado por tais elementos de ordem metafórica atuam como elementos de transição. E, num sentido contrário, na medida em que os compêndios de Cálculo empregam tal expediente no Cálculo em uma variável, e desconsideram-no no contexto de AC, reforçam elementos de ruptura que atuam contrário ao entendimento.

Situação de formulação. $\mathrm{Na}$ situação de formulação, admitimos que uma estratégia foi implementada ou, pelo menos, parcialmente implementada. Almouloud (2007, p. 38) esclarece que, neste momento, a troca de informações e mensagens entre os aprendentes é imprescindível.

Ademais, o resultado do debate a dialética "permite criar um modelo explícito que pode ser formulado com sinais e regras comuns". Um entrave, que apontamos, reside na dificuldade em determinar as intrincadas expressões analíticas que apresentamos, com recurso no software. (ver figura 5).

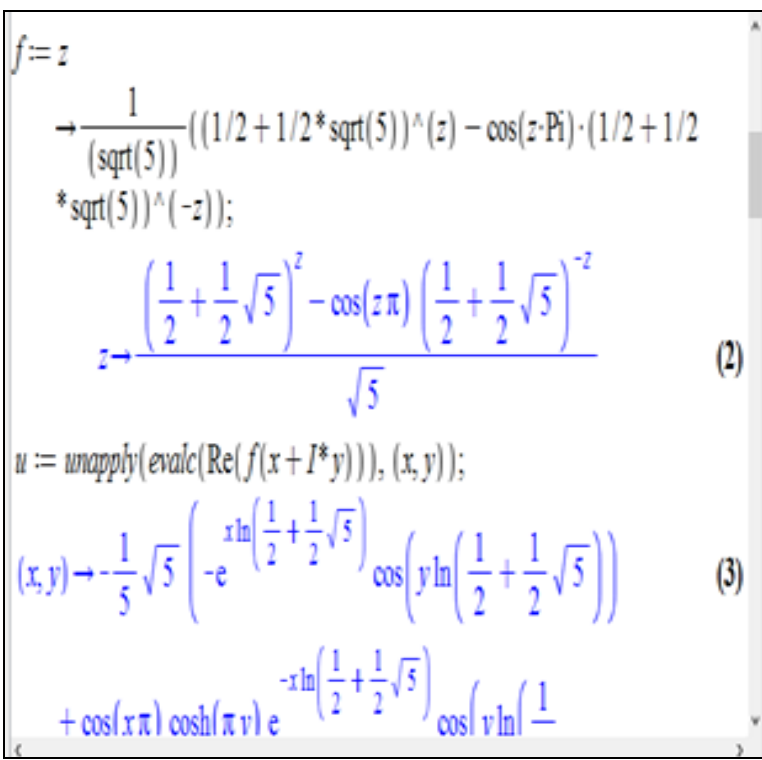

Figura 5 - Visualização/identificação da descrição analítica das partes real e imaginária

Analiticamente, escrevemos: 


$$
\begin{aligned}
& \operatorname{Re}(f(\mathrm{x}, \mathrm{y}))=-\frac{1}{5} \sqrt{5}\left(-e^{x\left(\frac{1}{2}+\frac{1}{2} \sqrt{5}\right)} \cos \left(y \cdot \ln \left(\frac{1}{2}+\frac{1}{2} \sqrt{5}\right)\right)\right) \\
& +\cos (\pi x) \cosh (\pi y) \cdot e^{x\left(\frac{1}{2}+\frac{1}{2} \sqrt{5}\right)} \cos \left(y \cdot \ln \left(\frac{1}{2}+\frac{1}{2} \sqrt{5}\right)\right) \\
& -\operatorname{sen}(\pi x) \operatorname{senh}(\pi y) e^{-x\left(\frac{1}{2}+\frac{1}{2} \sqrt{5}\right)} \operatorname{sen}\left(y \cdot \ln \left(\frac{1}{2}+\frac{1}{2} \sqrt{5}\right)\right) \\
& \operatorname{Im}(f(\mathrm{x}, \mathrm{y}))=-\frac{1}{5} \sqrt{5}\left(-e^{x\left(\frac{1}{2}+\frac{1}{2} \sqrt{5}\right)} \operatorname{sen}\left(y \cdot \ln \left(\frac{1}{2}+\frac{1}{2} \sqrt{5}\right)\right)\right) \\
& -\operatorname{sen}(\pi x) \operatorname{senh}(\pi y) \cdot e^{x\left(\frac{1}{2}+\frac{1}{2}-\sqrt{5}\right)} \cos \left(y \cdot \ln \left(\frac{1}{2}+\frac{1}{2} \sqrt{5}\right)\right) \\
& -\cos (\pi x) \cosh (\pi y) e^{-x\left(\frac{1}{2}+\frac{1}{2} \sqrt{5}\right)} \operatorname{sen}\left(y \cdot \ln \left(\frac{1}{2}+\frac{1}{2} \sqrt{5}\right)\right)
\end{aligned}
$$

Indubitavelmente, exigir dos alunos o cálculo das expressões analíticas anteriores se mostra uma tarefa fastidiosa. Ademais, os alunos, na fase de formulação, poderão mobilizar uma estratégia que envolve determinar a derivada da função $f(z)=\frac{\phi^{z}}{\sqrt{5}}-\frac{\cos (\pi z) \cdot \phi^{-z}}{\sqrt{5}}$, que poderá ser expressa por: $f^{\prime}(z)=f^{\prime}(x+i y)=$ $\frac{\log \phi \cdot \phi^{z}}{\sqrt{5}}-\frac{\left[\log \phi \cdot \cos (\pi z) \cdot \phi^{-z}-\pi \operatorname{sen}(\pi z) \cdot \phi^{-z}\right]}{\sqrt{5}}$

Apontamos o único entrave, caso as estratégias convirjam nessa direção, reside na predileção dos estudantes pelo caráter algoritmizado do tratamento das tarefas (ALVES, 2011) que, em certos casos, não estimula um real entendimento e apreensão do significado ou sentido das noções envolvidas.

Por outro lado, com arrimo no modelo computacional, podemos considerar a função $\operatorname{Re}(f(\mathrm{x}, \mathrm{y}))$, tomando o ponto $(1,1)$ e encontrar que $\operatorname{Re}(f(1,1))=3.484$. Em seguida, avaliamos as derivadas parciais da função anterior, que indicaremos na figura seguinte.

Logo em seguida, uma vez que dispomos com origem da intrincada expressão analítica das funções indicadas por $\operatorname{Re}(f(\mathrm{x}, \mathrm{y}))_{x} \quad$ e $\operatorname{Re}(f(\mathrm{x}, \mathrm{y}))_{y}$, que representam suas derivadas parciais em relação a ' $x$ ' e ' $y$ ', respectivamente.

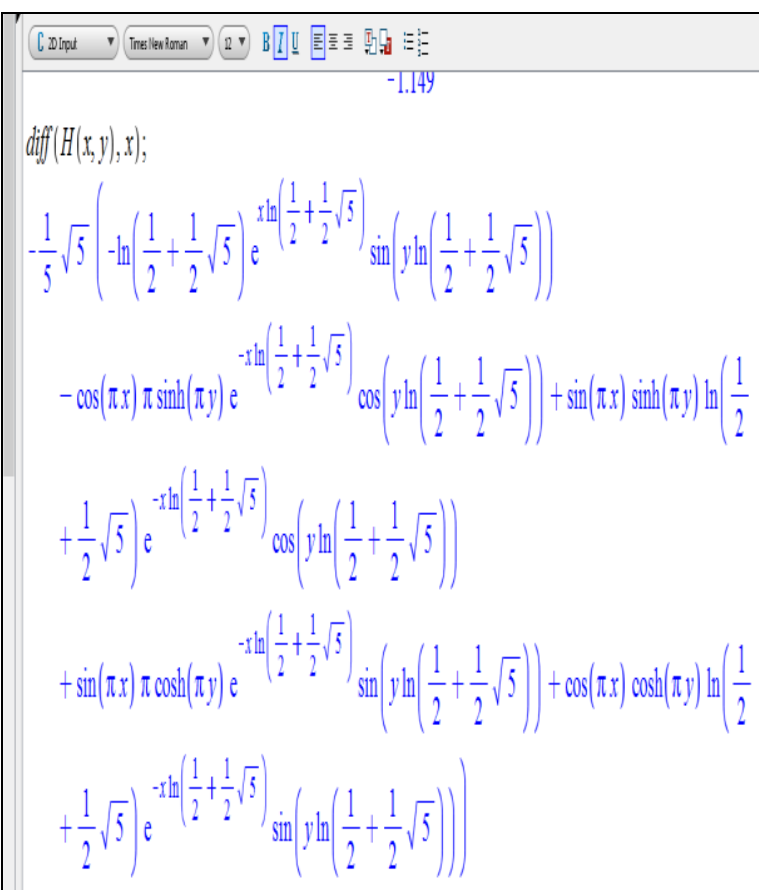

Figura 6 - Obtenção das derivadas parciais da parte real da função $\operatorname{Re}(f(\mathrm{x}, \mathrm{y}))$ no quadro analítico com recurso ao CAS Maple

Ademais, avaliamos com o software $\operatorname{Re}(f(1,1))_{x}=-5.702$ e $\operatorname{Re}(f(\mathrm{x}, \mathrm{y}))_{y}=8.014$. Ora, em consonância com o modelo do Cálculo em várias variáveis, o plano tangente à superfície que deve corresponder a parte real da função

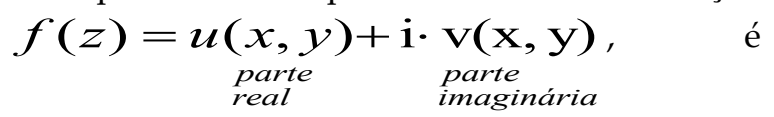
determinado pela seguinte expressão analítica $z=3.484+5.702(x-1)-8.014(y-1)$. Assinalamos o caráter fastidioso, caso o solucionador de problemas busque desenvolver apenas o trato analítico, sem o arrimo de um sistema computacional algébrico.

Agora, repetimos o procedimento anterior, considerando a parte imaginária que indicamos por $\operatorname{Im}(f(\mathrm{x}, \mathrm{y}))$. Nesse caso, devemos determinar $\mathrm{o}$ seguinte plano tangente à superfície $z=-1.149-5.702(x-1)-8.014(y-1)$, no ponto $(1,1,-1.149) \in \mathrm{IR}^{3}$.

Exibimos alguns ângulos de visualização oportunizando um maior entendimento da presente situação (ver figuras 7 e 8), fato que proporciona um ambiente de investigação e o debate científico entre os aprendentes. 


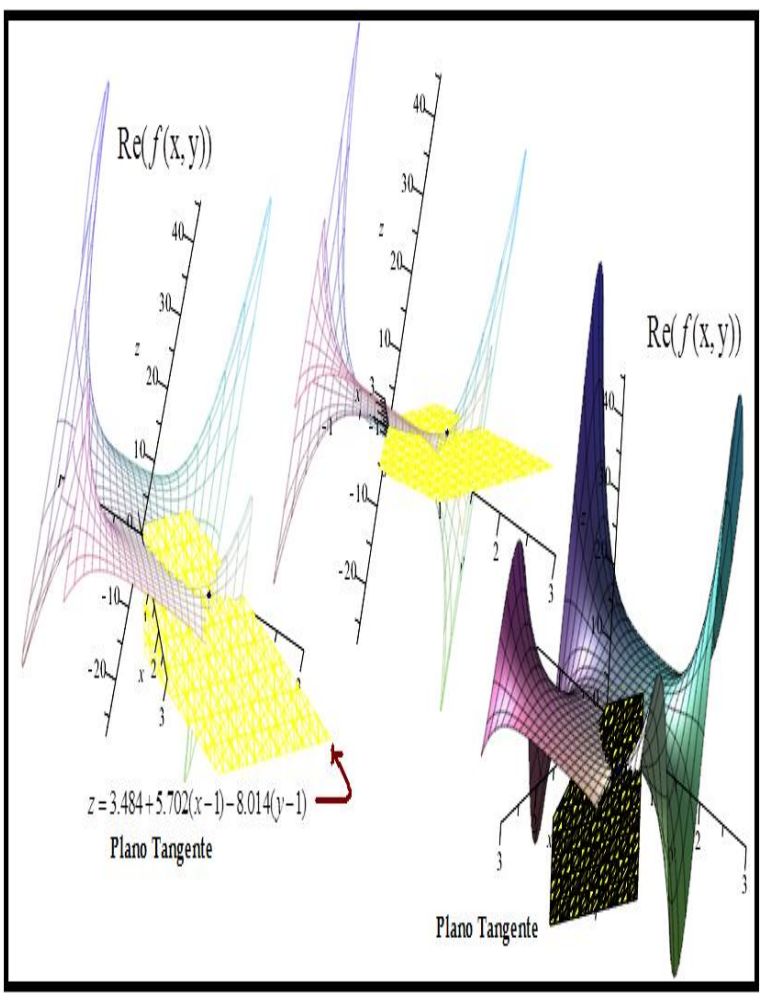

Figura 7 - Visualização de um plano tangente (na cor amarela) à superfície determinada pela função $\operatorname{Re}(f(\mathrm{x}, \mathrm{y}))$, no ponto $(1,1,3.484)$.

Fonte: Elaboração do autor

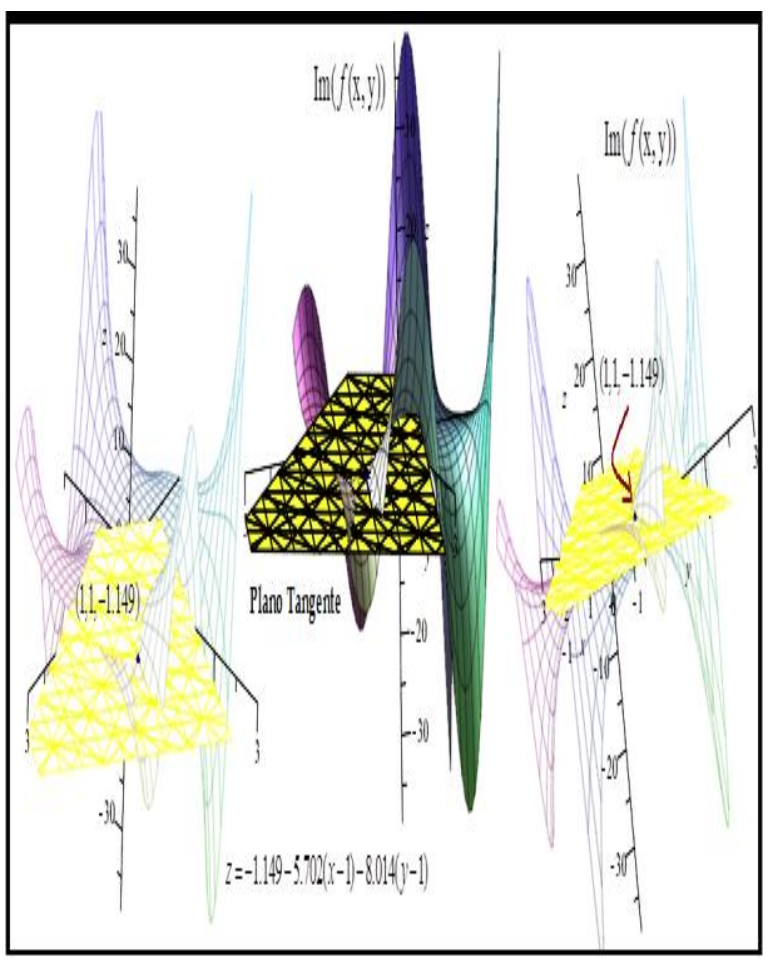

Figura 8 - Visualização de um plano tangente (na cor amarela) à superfície determinada pela função $\operatorname{Re}(f(\mathrm{x}, \mathrm{y}))$, no ponto $(1,1,3.484)$. Fonte: Elaboração do autor
Ora, com origem no cenário de aprendizagem envolvendo as figuras 3, 4, 5, 6, 7 e 8, de modo inexorável, estimulamos os estudantes, na fase dialética atual, na mobilização de conhecimentos tácitos que, com origem no modelo geométrico do Cálculo em uma variável real comunica que informação segundo a qual, uma função que admite uma reta tangente, num ponto do seu gráfico, goza da propriedade da diferenciabilidade ou derivabilidade, no caso de uma variável real (do ponto de vista local).

Depois de algum, no estudo do Cálculo em várias variáveis, os estudantes aprendem que uma função, nas variáveis reais ' $x$ ' e ' $y$ ', que admite, localmente, um plano tangente, determinado pela equação analítica $z=z_{0}+f_{x}\left(\mathrm{x}_{0}, y_{0}\right)\left(x-x_{0}\right)+f_{y}\left(\mathrm{x}_{0}, y_{0}\right)\left(\mathrm{y}-y_{0}\right)$ , goza da propriedade da diferenciabilidade, desde que suas derivadas parciais sejam contínuas no referido ponto considerado.

Dessa forma, o caráter de diferenciabilidade da função $f(z)=\mathrm{u}(\mathrm{x}, \mathrm{y})+\mathrm{i} \cdot \mathrm{v}(\mathrm{x}, \mathrm{y})$, poderá ser significado a partir da "verificação visual" (ALVES, 2011) dos estudantes da existência agora de dois planos tangentes, correspondentes à sua parte real e à sua parte imaginária. Todavia, tais informações podem atuar, ainda nessa fase, em caráter provisório e, a garantia de maior formalismo poderá ser perseguido na próxima fase didática (fase de validação).

Ademais, na mesma tarefa, os aprendizes devem perquirir a propriedade característica das funções harmônicas. Mais uma vez, acentuamos que a mesma propriedade pode ser encontrada no contexto do Cálculo em várias variáveis e, resignificado no contexto de AC. Isso posto, identificamos um elemento capaz de atuar como elementos de transição.

Para tanto, com arrimo na figura 9, divisamos as curvas de nível determinadas pela parte real da função $f(z)$. Enquanto que, ao lado direito, vemos as curvas de nível determinadas pela parte imaginária da função $f(\mathrm{z})$. Os saberes intitucionalizados na etapa de estudos acadêmicos anteriores devem garantir o domínio das propriedades relacionadas com a noção de curva de nível. Shokranian (2011, p. 133)) ensina que, no caso em que lidamos com funções, em duas variáveis reais, ditas harmônicas, devemos reparar o comportamento da intersecção das curvas (ver figura 10). 
Do ponto de vista analítico formal, expressamos $\quad \nabla^{2} u(x, y)=\frac{\partial^{2} u}{\partial x \partial x}+\frac{\partial^{2} u}{\partial y \partial y}$. inspeção standard, no caso de funções na variável complexa, se restringe na verificação da condição anterior, relativamente às partes real e imaginárias da função $f(\mathrm{z})$.

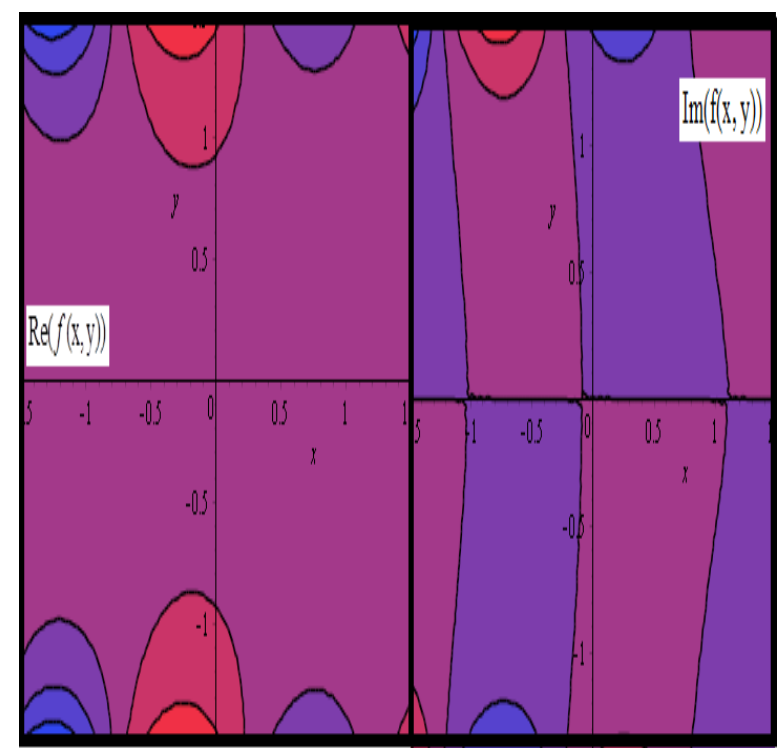

Figura 9 - Visualização das curvas de nível determinadas pela parte real e imaginárias da função $f(z)$ com recurso ao CAS Maple

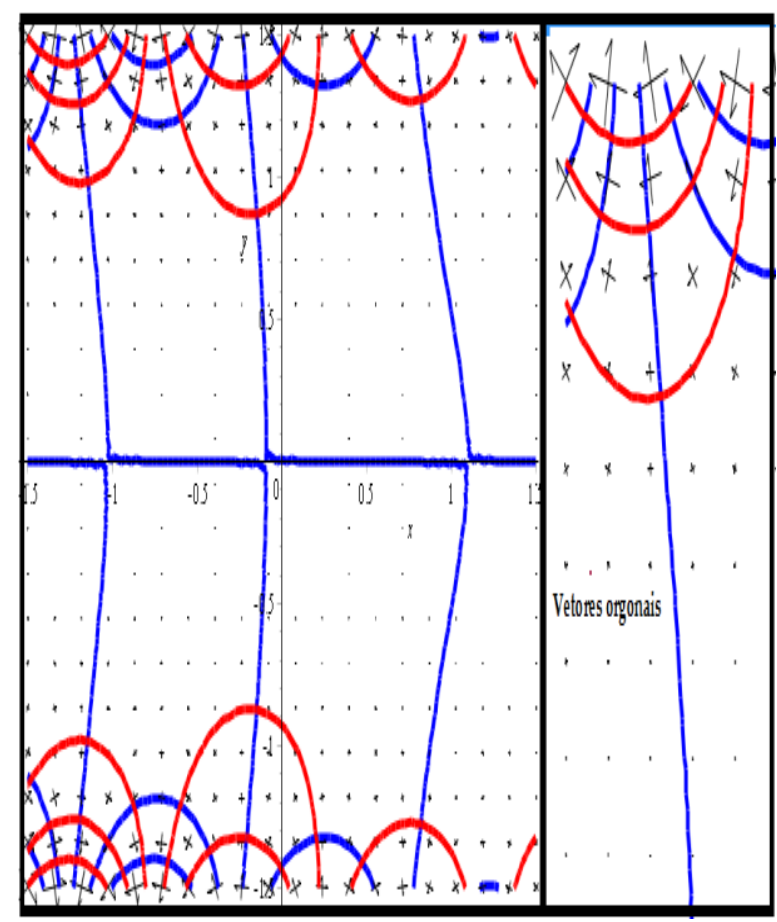

Figura 10 - Os vetores determinados pelas curvas de nível se encontram ortogonalmente como indica o CAS Maple
Podemos verificar, por intermédio de uma inspeção pormenorizada, que seu encontro ocorre de modo que, os vetores determinados por um campo, se mostram ortogonais (ver figura 10 ao lado direito). Tal comportamento no quadro geométrico transmite uma propriedade necessária para que a função $f(z)$ seja harmônica (FLANIGAN, 1972; GONG, 2001; SHOKRANIAN, 2011), isto é, possua o Laplaciano igual a zero. Podemos comparar, agora, os dados da figura 11, com os dados fornecidos pelo CAS Maple.

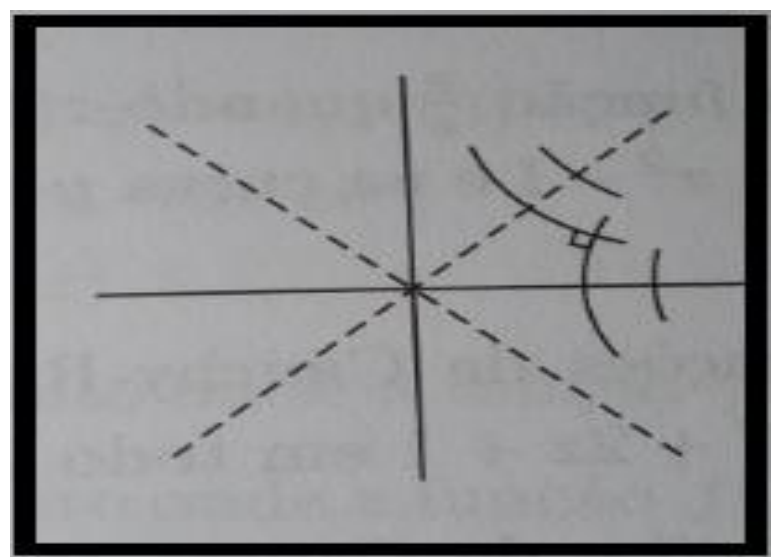

Figura 11 - Shokranian (2011, p. 137) transmite a ideia geométrica relacionada com a noção de funções que possuem o laplaciano zero

Reparemos, ainda, que no enunciado da situação-problema I, transferimos a responsabilidade para o estudante decidir sobre a propriedade da diferenciabilidade (devolução). Posto isso, decidimos evitar as mensagens indicativas, recorrentes nos enunciados de tarefas que, de modo preponderante, reduzem o papel do aprendiz ao cálculo e o emprego de algum "malabarismo algébrico" comunicado pelo professor em momentos anteriores.

Nessa categoria de questões e exercícios, a instrução normativa de calcular e avaliar, desconsiderando o sentido da situação proposta, se transforma no fim e único objetivo.

Situação de validação: Nessa fase, num contexto do "debate da certeza das asserções" (ALMOULOUD, 2007, p. 40), os dados produzidos com origem nas interações dialéticas dos estudantes da fase anterior, com as informações e inferências empregadas afim de obter a certeza das relações estabelecidas.

Todavia, salientamos que boa parte dos argumentos anteriores se mostram apoiados no 
modelo do Cálculo em várias variáveis, o que estimula a readaptação dos conhecimentos dos estudantes e reforça, por tal via, um elemento cognitivo de transição. Num sentido contrário, quando estimulamos, de modo restrito, apenas estratégias que encontramos em $\mathrm{AC}$ e os estudantes não distinguem sua ligação/vinculo com os saberes apreendidos anteriormente, reforçamos elementos de ruptura (ALVES, 2011).

Situação de institucionalização. Ora, o conhecimento matemático que o expert deverá convencionar ou fixar (ARTIGUE, 1984, p. 8), seguindo os rituais acadêmicos, indicando o estatuto cognitivo de um novo saber, rico em relações conceituais e, como apontamos, inclusive com relações com a Análise Complexa.

Neste momento, de modo mais visível, o professor deve assumir o papel proeminente na fase atual (ALMOULOUD, 2007, p. 42), uma vez que, a determinação da forma e do conteúdo do saber para o qual ele tenciona aderir um determinado estatuto oficial institucionalizado.

Nessa fase dialética, o professor deverá conduzir os aprendizes na percepção de que a função $f(z)=\frac{1}{\sqrt{5}}\left[\phi^{z}-\cos (\pi z) \cdot \phi^{-z}\right]$ pertence, na verdade, a uma classe bem mais geral de funções na variável complexa, a saber, as funções que podem ser desenvolvidas em séries de potências. Com efeito, sabemos que $\cos (\pi z)=\sum_{i=0}^{\infty} \frac{(-1)^{i}}{(2 i) !} \cdot(\pi z)^{2 i} \quad$ e que $\phi^{z}=\sum_{i=1}^{\infty} \frac{g^{(\mathrm{i})}(0)}{\mathrm{i} !} \cdot z^{i}$. Isto é, a função $f(z)$ é, na verdade, uma diferença e produto de funções infinitamente diferenciáveis, na variável complexa. Daí, por teorema, deverá pertencer à classe das funções infinitamente diferenciáveis.

Outrossim, na fase de institucionalização, o professor poderá enunciar e demonstrar o seguinte teorema: seja $f(z)=u(z)+i v(\mathrm{z})$ uma função na variável complexa, contínua no ponto $z_{0}=\left(x_{0}, y_{0}\right) \in \mathrm{IR}^{2}$, cujas derivadas parciais $u_{x}(\mathrm{x}, \mathrm{y}), u_{y}(\mathrm{x}, \mathrm{y}), \mathrm{v}_{x}(\mathrm{x}, \mathrm{y}), \mathrm{v}_{y}(\mathrm{x}, \mathrm{y})$ existem no ponto e são contínuas. Então, a função será derivável no sentido da variável complexa (CECÍLIA \& BERNADEZ, 2008; CONWAY, 1978; LINS NETO, 1993; SOARES, 2014; SHOKRANIAN, 2011)
Nesse sentido, registramos as considerações de Alves (2011), no sentido de identificar elementos que podem atuar como entraves ao entendimento. Todavia, com o uso da formulação prevista do teorema anterior, na ação de institucionalização do saber científico, os estudantes poderão perceber uma readaptação de conhecimentos estudados no âmbito do Cálculo em várias variáveis, no contexto da AC.

Assim, tendo como escopo a fixação/determinação do estatuto oficial de um saber científico (ALMOULOUD, 2007, p. 40), o professor poderá identificar todas as implicações e relações conceituais surpreendentes do modelo matemático discutido na situação-problema, inclusive, as possíveis ligações conceituais, posto que, a função $f(z)=\frac{\phi^{z}-\cos (\pi z) \cdot \phi^{-z}}{\sqrt{5}}$ constitui na verdade, uma especialização ou generalização da Sequência Generalizada de Fibonacci - SGF (ALVES, 2015b; 2015c).

Na situação seguinte, tencionamos explorar apenas o quadro de representação analítica dos conceitos relacionados com o processo de integração na variável complexa.

Situação-problema II: decidir o comportamento da seguinte integral $I(a)=\int_{0}^{2 \pi} \frac{d \theta}{\cos ^{2}(\theta)+a^{2}}, a>0$.

Comentários: no enunciado da situação anterior transferimos a responsabilidade a aprendiz a tarefa de concluir pela convergência ou divergência da integral correspondente.

Situação de ação. Consideremos que $z=e^{i \theta} \therefore d z=i \cdot e^{i \theta} d \theta=i z d \theta$, isto é, escrevemos $d \theta=\frac{d z}{i \cdot z}$. Por outro lado, reparemos que se considerarmos o conjunto $\left.S^{1}=\{z \in] \mid\|z\|=1\right\} \quad$ e, $\quad$ reparemos $z=e^{i \theta}=\cos (\theta)+i \operatorname{sen}(\theta)$ e, ai, escrevemos $z^{-1}=e^{-i \theta}=\cos (-\theta)+i \operatorname{sen}(-\theta)=$ $=\cos (\theta)-i \operatorname{sen}(\theta)$.

Daí, veremos ainda que $z+z^{-1}=2 \cos (\theta)$ e $z-z^{-1}=2 i \operatorname{sen}(\theta)$.

O cálculo anterior deve auxiliar a mudança de variáveis na integral $I(\theta)$, na medida em que teremos as relações $\cos (\theta)=\frac{z^{2}+1}{2 z}$. 
Mas, reparemos ainda que:

$\frac{d \theta}{\cos ^{2}(\theta)+a^{2}}=\frac{d z}{i z} \frac{1}{\left(\frac{z^{2}+1}{2 z}\right)^{2}+a^{2}}=\frac{d z}{i z} \frac{4 z^{2}}{\left(z^{2}+1\right)^{2}+4 a^{2} z^{2}}$

$=\frac{4 z d z}{i\left[\left(z^{2}+1\right)^{2}+4 a^{2} z^{2}\right]}=\frac{4 z \cdot d z}{i \cdot D(z)}$, aonde

indicamos $D(z)=\left[\left(z^{2}+1\right)^{2}+4 a^{2} \cdot z^{2}\right]$.

Situação de formulação. De imediato, os estudantes devem constatar a decomposição $\left(z^{2}+1\right)^{2}+4 a^{2} z^{2}=0 \therefore z^{4}+2 z^{2}+1+4 a^{2} z^{2}=0 \quad$ e, portanto, escrevemos $\left(z^{2}\right)^{2}+\left(2+4 a^{2}\right) \cdot z^{2}+1=0$.

Ora, resolvendo tal expressão, fazendo a substituição $t=z^{2} \therefore t^{2}+\left(2+4 a^{2}\right) \mathrm{t}+1=0 \leftrightarrow t=$ $\frac{-2+4 a^{2} \pm \sqrt{4+8 a^{2}+16 a^{4}-4}}{2}=\frac{-2+4 a^{2} \pm 2 a \sqrt{2+4 a^{2}}}{2}$.

Mas, com origem no resultado anterior, podemos depreender que $D(z)=0$, com as raízes $\left\{\lambda_{1},-\lambda_{1}, \lambda_{2},-\lambda_{2}\right\}$. Por outro lado, notemos que $\lambda_{1}=\mathrm{i}\left(\sqrt{a^{2}+1}-a\right), \lambda_{2}=\mathrm{i}\left(\sqrt{a^{2}+1}+a\right)$. Com efeito, vejamos, por exemplo, que $\lambda_{1}^{2}=-\left(a^{2}+1-2 a \sqrt{a^{2}+1}+a^{2}\right) \therefore \lambda_{1}^{2}+1=$ $=2 a \sqrt{a^{2}+1}-2 a^{2}$. Logo em seguida, vemos que $\left(\lambda_{1}^{2}+1\right)^{2}=8 a^{4}+4 a^{2}-8 a^{3} \sqrt{a^{2}+1} . \quad \mathrm{E}$, ainda, encontramos $4 a^{2} z^{2}=-8 a^{4}-4 a^{2}+8 a^{3} \sqrt{a^{2}+1}$. $\mathrm{Ou}$ seja, verificamos que $D\left(\lambda_{1}\right)=\left[\left(\lambda_{1}^{2}+1\right)^{2}+4 a^{2} \lambda_{1}^{2}\right]=0$.

Observemos que $0<\left|\lambda_{1}\right|<1<\left|\lambda_{2}\right|$. E, desde que a $>0$, apenas duas raízes estão no interior da região $S^{1}=\{z \in \square \mid\|z\|=1\}$, escrevemos: $I(a)=\int_{0}^{2 \pi} \frac{d \theta}{\cos ^{2}(\theta)+a^{2}}=\int_{S^{1}} \frac{4 z d z}{i D(z)}$.

Então, podemos escrever: $=\frac{4}{i} \int_{S^{1}} \frac{z d z}{D(z)}=$ $=\frac{4}{i}(2 \pi i)\left[\operatorname{Re} s\left(\frac{z d z}{D(z)}, \lambda_{1}\right)+\operatorname{Re} s\left(\frac{z d z}{D(z)},-\lambda_{1}\right)\right]=$ $=8 \pi \cdot\left[\operatorname{Re} s\left(\frac{z d z}{D(z)}, \lambda_{1}\right)+\operatorname{Re} s\left(\frac{z d z}{D(z)},-\lambda_{1}\right)\right]$
Mas, vemos que $D(z)=\left[\left(z^{2}+1\right)^{2}+4 a^{2} z^{2}\right]=$ $=\left(z-\lambda_{1}\right)\left(z+\lambda_{1}\right)\left(z-\lambda_{2}\right)\left(z+\lambda_{2}\right)$ e, entretanto, apenas as raízes $\lambda_{1},-\lambda_{1}$ constituem pólos simples na região de nosso interesse. Outrossim, vimos que $D(z)=z^{4}+2 z^{2}+1+4 a^{2} z^{2}$ e, então $D^{\prime}(z)=4 z^{3}+4 z+8 a^{2} z=4 z^{3}+4\left(1+2 a^{2}\right) z$.

Mas, procedemos o cálculo da primeira expressão $\operatorname{Re} s\left(\frac{z d z}{D(z)}, \lambda_{1}\right)=\frac{h\left(z_{0}\right)}{g^{\prime}\left(z_{0}\right)}=$ $=\frac{\lambda_{1}}{D^{\prime}\left(\lambda_{1}\right)}=\frac{\lambda_{1}}{4 \lambda_{1}^{3}+4\left(1+2 a^{2}\right) \lambda_{1}}=\frac{1}{4 \lambda_{1}^{2}+4\left(1+2 a^{2}\right)}$ $=\frac{1}{-4\left(\sqrt{a^{2}+1}-a\right)^{3}+4\left(1+2 a^{2}\right)}=$ $\frac{1}{-4\left(2 a^{2}+1-2 a \sqrt{a^{2}+1}\right)+4+8 a^{2}}=\frac{1 / 8}{a \sqrt{a^{2}+1}}, \mathrm{a}>0$

E, com origem no mesmo argumento, os estudantes deverão encontrar: $\operatorname{Re} s\left(\frac{z d z}{D(z)}, \lambda_{2}\right)=$ $=\frac{h\left(z_{0}\right)}{g^{\prime}\left(z_{0}\right)}=\frac{\lambda_{2}}{D^{\prime}\left(\lambda_{2}\right)}=\frac{\lambda_{2}}{4 \lambda_{2}^{3}+4\left(1+2 a^{2}\right) \lambda_{2}}$, e repetindo o expediente anterior, devemos encontrar a mesma expressão.

Por fim, com origem na depuração das estratégias discutidas, os estudantes deverão, pelo menos, se aproxima do seguinte resultado

$$
\begin{aligned}
& I(a)=\int_{0}^{2 \pi} \frac{d \theta}{\cos ^{2}(\theta)+a^{2}}= \\
& =8 \pi\left[\operatorname{Res}\left(\frac{z d z}{D(z)}, \lambda_{1}\right)+\operatorname{Res}\left(\frac{z d z}{D(z)},-\lambda_{1}\right)\right] \\
& =8 \pi \frac{1 / 8}{a \sqrt{a^{2}+1}}+8 \pi \frac{1 / 8}{a \sqrt{a^{2}+1}}=\frac{2 \pi}{a \sqrt{a^{2}+1}}
\end{aligned}
$$

Situação de validação. Almouloud (2007, p. 39) explica que "é a etapa na qual o aprendiz deve mostrar a validade do modelo por ele criado, submetendo a mensagem matemática (modelo de situação) ao julgamento de um interlocutor".

Assinalamos um caráter eminentemente linear perseguido na fase anterior. Com efeito, desde que optamos por um quadro analítico de 
exploração dos conceitos, grosso modo, se o sujeito compreende ou tem memorizado os resultados fundamentais relacionados com a Teoria do Resíduo, possivelmente, agirá em situação, embora, defendemos posição de que, num momento de aplicação empírica (experimentação), a produção de conjecturas apoiadas pela visualização exige maior vigilância na mediação do professor (ALVES, 2011, 2013).

Antes de descrevermos a fase dialética seguinte, assinalamos a advertência de Almouloud (2007, p. 40) quando menciona que "se feita muito cedo, a institucionalização interrompe a construção do significado, impedindo uma aprendizagem adequada e produzindo dificuldades para o professor e os alunos".

Situação de institucionalização. Brousseau (1986, p. 342) comenta que “a produção no ensino de conhecimento matemático demanda um esforço de transformação de um conhecimento em saber matemático [...]", Assim, ele indica que a epistemologia do professor atuará no sentido de não personalização e não contextualização, e que buscará eliminar os traços históricos que determinaram sua aparição.

Ora, a distinção de Brousseau é clara, no sentido de pontuar um conhecimento mobilizado, localizado e particular, pertencente a um grupo de alunos e, gradualmente, receberá status de maior generalidade, pois, enquadrado num corpus teórico formal, cujo viés estruturalista se mostra evidenciado e distinguido na academia.

$\mathrm{Na}$ presente situação, o modelo ou teorema que deve validar e garantir o confronto e estabelecimento final das conjecturas produzidas, diz respeito ao seguinte teorema.

Teorema (teorema dos resíduos). Sejam $\gamma: I \rightarrow C$ um caminho fechado simples e $R$ a região interior a $\gamma(\theta)$. Suponhamos que $\gamma$ esteja orientada positivamente com respeito a região $R$. Seja uma função $f: U \rightarrow C$ uma função holomorfa que possui um número finito de singularidades isoladas em $R$, digamos $z_{1}, z_{2}, z_{3}, \ldots, z_{n}$.

Supondo ainda a seguinte condição $U \supset \bar{R}-\left\{z_{1}, z_{2}, z_{3}, \ldots, z_{n}\right\}$. Então, teremos que $\int_{\gamma} f(z) d z=2 \pi i \sum_{i=1}^{n} \operatorname{Re} s\left(f(z) d z, z_{i}\right)$.
Tendo em vista a escolha do público alvo, a demonstração do teorema anterior poderá extrapolar os limites dos saberes científicos a serem exigidos dos estudantes. Desse modo, cabe ao professor, em consonância com as habilidades e o domínio dos prerrequisitos do grupo, decidir por sua demonstração formal em sala de aula.

Para concluir a presente seção em que indicamos, nos parágrafos anteriores, as duas situações-problema, acentuaremos algumas reflexões que detêm o potencial de impulsionar ulterior investigação no âmbito do ensino de AC.

De modo preliminar, vale recordar que:

\begin{abstract}
No sistema clássico de ensino, o professor não controla o meio no qual a situação é apresentada, nem os conhecimentos elaborados pelos estudantes. $\mathrm{Ou}$ o aluno aprende sempre em situação, e tal situação é construida deliberadamente ou não pelo professor. Os exemplos, os exercícios encontrados, a ordem da aparição das noções, formam a base do meio para a aprendizagem e, a partir da mesma, os conhecimentos deverão se formar, ao mesmo tempo precisos ou errôneos, sem que o controle total do professor seja possível" (MARGOLINAS, 1995, p. 344).
\end{abstract}

Assumimos posição parcialmente concorde com Margolina (1995). Com efeito, lidamos, nas duas situações passadas, com um ambiente de investigação extremamente matematizado e "situações construidas são caracteristicas do conhecimento em jogo" (MARGOLINAS, 1995, p. 343), ou seja, desde que optamos por mobilizar um conhecimento relacionado com a noção de diferenciabilidade e, no segundo caso, com a noção do processo de integração na variávei complexa, podemos declarar que, as caracteristica matemático-epistemológicas em jogo determinam, em maior ou em menor substância, as estratégias validadas pelos sujeitos.

Por outro lado, "certas demonstrações podem ocorrer sem a aplicação de uma sequência finita de especificações que produzem seu avanço. Existe, pois, um algoritmo automático produtor de uma demonstração dada" (BROUSSEAU, 1976, p. 102).

Não obstante, em que pese o caráter intrincado e abstracionista do corpus teórico subjacente em ambas as situações abordadas, não podemos esperar certa automacidade de um 
algoritmo produtor de resultados precisos e isentos de incorretudes, tendo em vista que a exigência da consulta das condições que permitem sua aplicabilidade deve ser discutida na situação dialética de validação.

\section{Alguns elementos da análise $a$ posteriori}

Doravante, indicaremos elementos que não podem ser negligenciados numa eventual aplicação empírica de todo o aparato conceitual descrito nas seções anteriores. Isso posto, acentuamos que Almouloud (2007, p. 177) adverte que a análise a posteriori não se constitui como uma crônica da classe, todavia, uma análise feita à luz da análise a priori, dos fundamentos teóricos assumido, das hipóteses de trabalho, de investigação e da problemática da pesquisa. Recordamos, porém, que nossa discussão não apresentará dados empíricos, entretanto, nossa proposta de ED proporciona antevermos determinados aspectos, de acordo com os pressupostos que elegemos nas seções anteriores.

Nesse sentido, recordamos que Artigue (2013, p. 10) comenta, em relação ao o uso da tecnologia, que "nós perdemos nossa inocência, nós compreendemos agora, de modo melhor, as razões de ser das dificuldades dos estudantes".

Ora, Artigue faz um balanço do uso da tecnologia para o ensino na universidade. Em nosso caso, defendemos a modificações da mediação do professor, tendo em vista o uso do CAS Maple. E, no bojo das variáveis microdidáticas, acentuamos que, determinadas estratégias dos estudantes, caracterizadas pela produção de conjecturas preliminares, deverão requerer análises cognitivas, com o arrimo de teorias de base cognitivistas, como, por exemplo, as formulações propostas por Duval (1995) ou Vergnaud (1981).

Ademais, tendo em vista que o objetivo de uma análise a posteriori é "relacionar as observações com os objetivos definidos a priori e estimar a reprodutibilidade e, também, a regularidade dos fenômenos didáticos identificados" (ALMOULOUD, 2007, p. 177), acentuaremos alguns elementos merecedores de atenção, para uma eventual aplicação experimental de todo aparato erigido nas seções anteriores.
Logo, a partir de uma validação externa, tomando como referência outros estudos realizados e, como menciona Almouloud, com o escopo de prever a regularidade de determinados fenômenos didáticos, assinalamos: (i) os sistema de representação dos objetos conceituais e processos matemáticos em AC podem produzir entraves à evolução das estratégias implementadas pelos estudantes; (ii) a desconsideração da tecnologia pode concorrer para a manifestação de elementos de ruptura (ALVES, 2011) identificáveis nos dados empíricos; (iii) a exploração da tecnologia poderá concorrer para a manifestação de elementos de transição (ALVES, 2011) em dados empíricos, tendo em vista a exploração da visualização; (iv) identificar modificações possíveis no estudo proposto, tendo em vista o uso de outros softwares, em caráter de complementaridade (ALVES, 2014b); (v) as situações que discutimos na seção anterior se apresentam como situações didáticas (MARGOLINAS, 1995, p. 342), em contraposição das situações a-didáticas (BROUSSEAU, 1986); (vi) a devolução das situações didáticas (MARGOLINAS, 1995, p. 342) não envolvem a incumbência dos estudantes no que concerne ao domínio da sintaxe do CAS Maple; (vii) para uma análise eficiente de dados empíricos, tendo em vista a natureza do modelo matemático discutido, indicamos teorias de base cognitivista, que abordam a internalização de conceitos científicos no locus acadêmico (TALL, 1991); (viii) diante da escassez de trabalhos acadêmicos empíricos, a não ser discussões que permanecem num campo introdutório de $\mathrm{AC}$ (CHAVEZ, 2014; DANENHOWER, 2000; TIROSH \& ALMOG, 1989), sugerimos comparar com os resultados de outras pesquisa no Cálculo em Várias Variáveis, afim de efetuar a análise da sequência didática (ALMOULOUD, 2007, p. 178); (ix) a ED permite ao professor "visar todo um repertório de situações próprias de colocar em cheque as representações falsas dos alunos [...]" (BROUSSEAU, 1986c, p. 278).

\section{Considerações finais}

No atual escrito, abordamos alguns elementos teóricos, atinentes ao âmbito de um design de investigação em Didática da Matemática, que se enquadra na vertente francesa da pesquisa científica na área, tendo como tema alguns 
assuntos que se inserem na Análise Complexa AC.

Com característica marcante de uma proposta de investigação em ED, não nos furtamos de considerar seu campo histórico-epistemológico. E, nesse sentido, Medvedev (1991, p. 63) acentua que a consolidação da teoria das funções na variável complexa pode ser apenas constatada e consolidada no século XX (ver seção 4).

O episódio histórico que relatamos na fase preliminar da ED, se torna relevante, na medida em que adquirimos a possibilidade de compreender os percalços enfrentados pelos matemáticos profissionais, dentre eles, C. Cauchy e E. Gousat, no intuito de determinar as bases sólidas de fundamentação do teorema, hodiernamente conhecido por LoomannMenchoff e, nem sempre abordado nos compêndios especializados (DEBNATH, 2015).

Sua análise permite constarmos que, nos estágios preliminares, a investigação do profissional fica à mercê das habilidades inventivas (HADAMARD, 1945) e intuitivas do matemático. E, tais informações que se inserem na etapa de análise epistemológica do conteúdo (analises preliminares), e que nos influenciaram na descrição, estruturação e previsão das etapas que comentamos na situaçao-problema I (análise a priori).

Em contrapartida, constatamos, na segunda situação-problema, um trato eminentemente analítico e formal. Com efeito, ao passo em que a visualização assumiu papel imprescindível no entendimento do caráter de diferenciabilidade da função $f(z)=\phi^{z}-\cos (\pi z) \cdot \phi^{-z} / \sqrt{5}$, vimos, ao decurso da resolução da integral $I(a)=\int_{0}^{2 \pi} \frac{d \theta}{\cos ^{2}(\theta)+a^{2}}$, os conhecimentos de certas manipulações formais, condicionados pelo conhecimento e domínio das definições e teoremas, constituem condição sine qua non para o progresso da ação do estudante na investigação proposta. Nessas circunstâncias, a atividade de produção de conjecturas, essencial para o engajamento na situação-problema II, se mostra comprometida (ALVES, 2011).

Outrossim, do ponto de vista da atividade de preparação do professor para o momento didático que apresentamos (propomos), o professor poderá deparar um terreno mais natural e fértil, no que concerne à exploração dos elementos formais e logicizados, fato que prejudica a evolução satisfatória das situações de ação e formulação.

$\mathrm{Na}$ figura 11, assinalamos os elementos de transição discutidos por Alves (2011), no contexto do Cálculo em várias variáveis, que representa um prerrequisito imprescindível para os estudos em AC. Na figura, divisamos a ideia geométrica, recorrentemente explorada pelos livros de Cálculo em uma variável real, envolvendo a derivabilidade de uma função $y=f(x)$, pelo fato de admitir um a reta tangente. Não obstante, Alves (2011) aponta um elemento de ruptura, de ordem metodológica, uma mediação que desconsidera a readaptação da ideia intuitiva anterior, para o contexto do Cálculo em várias variáveis.

Com efeito, nesse caso, ao lado direito, divisamos a existência de uma reta tangente à superfície definida no espaço, pela função $z=f(x, \mathrm{y})=10-x^{2}-y^{2}$. $\mathrm{E}, \quad$ com os argumentos discutidos, podemos determinar um plano tangente à superfície.

Ora, ao longo da situação-problema I, indicamos um cenário de aprendizagem que proporciona a ideia da diferenciabilidade, do ponto de vista geométrico, para funções na variável complexa. E, nesse último caso, os alunos poderão deparar a existência de dois planos tangentes (ver figuras 7 e 8 ). Outrossim, exibimos na figura 12 , um esquema mnemônico de elementos que exigem uma exploração visual, tendo em vista evitarmos, do ponto de vista das variáveis didáticas, certos elementos de ruptura.

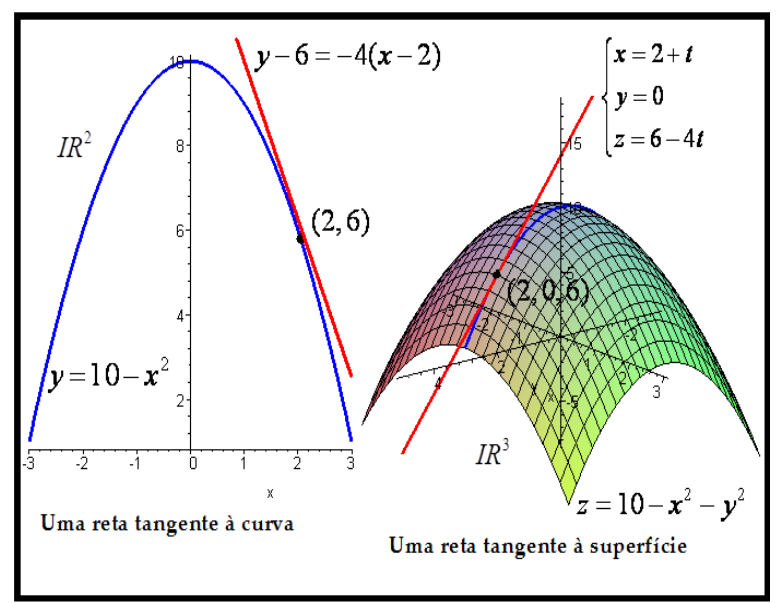

Figura 11 - Exploração dos elementos de transição com recurso na tecnologia (ALVES, 2011, p. 234) 


$$
\begin{aligned}
& y=f(x) \text { (um a reta tangente) } \\
& z=f(x, y) \text { (um plano tangente) } \\
& f(z)=\operatorname{Re}(f(z))+i \operatorname{Im}(f(z) \\
& \text { (dois planos tangentes) }
\end{aligned}
$$

Figura 12 - Exploração dos elementos de transição no ensino de AC. Fonte: Elaboração do autor

A figura 12, pode estimular uma perspectiva acentuada por Soares (2014, p. 34), na medida em que acentua a importância de vislumbrarmos funções do tipo $f(z)=\mathrm{u}(\mathrm{z})+\mathrm{iv}(\mathrm{z})$, na variável complexa, bem como a reversibilidade de interpretação, por parte do aluno, quando grafamos o símbolo, nas variáveis reais, que indicamos $f(\mathrm{x}, \mathrm{y})=(\mathrm{u}(\mathrm{x}, \mathrm{y}), \mathrm{v}(\mathrm{x}, \mathrm{y})) \in \mathrm{IR}^{2}$, perspectiva que exploramos na situação $\mathrm{I}$. Outrossim, o esquema mnemônico que buscamos encerrar na figura 12 traz um apelo ao "componente heurístico" (BROUSSEAU, 1998, p. 117) que, em muitos casos, se mostra negligenciado ou desconsiderado.

Por fim, deve constitui parte das análise do ensino atual de AC, uma abordagem de autores de compêndios especializados (NEEDHAM, 2000; GREENE \& KRANTZ, 2006; KRANTZ, 1990; SCHWERDTFEGER, 1979; SPIEGEL et all, 2009) que buscam envidar esforços, no sentido de transmitir determinadas ideias intuitivas, todavia, como apreciamos na figura 12, tais tentativas ainda não exploram, como poderiam fazê-lo, as potencialidades dos softwares atuais de Matemática.

Finalmente, a presente proposta teórica de uma ED, detém o potencial de aplicação empírica em sala de aula, sua predição, reprodução e replicação, tendo em vista o extenso repertório de elementos abordados e sistematizados até aqui, com o escopo de proporcionar o acúmulo de conhecimentos didáticos sobre o ensino de Análise Complexa.

\section{Referências}

ALVES, Francisco. R. V. Visualização de Teoremas em Análise Complexa: exemplos no contexto da Transição Complexa do Cálculo
TCC. In: Revista Sinergia, 16(1), p. 65 - 76, 2015a.

ALVES, Francisco. R. V. Sobre a evolução do modelo de Fibonacci: a classe das funções hiperbólicas de Fibonacci. In: Revista VYDIA Educação, 35(1), p. 133 - 146, 2015b.

ALVES, Francisco. R. V. Sequência Generalizada de Fibonacci e suas relações com o número de ouro. In: Boletim Cearense de Educação e História da Matemática. 2(6), p. 1 - 4, 2015c.

ALVES, Francisco. R. V. Engenharia Didática para o Teorema da Função Implícita: análise preliminares e a priori. In: Revista Brasileira de Ensino de Ciência e Tecnologia, 7(3), p. 148 -168 , 2014a.

ALVES, Francisco. R. V. Técnica Computacional para o Ensino de Matemática Computational Technique for Teaching Mathematics $C T^{2} M$. In: EM TEIA: Revista de Educação Matemática e Tecnológica Iberoamericana, 5(2), p. 1 - 9. 2014b.

ALVES, Francisco. R. V. Aplicações no Ensino de Variável Complexa: uma discussão sobre o uso dos softwares Geogebra e CAS Maple. In: Revista do Instituto GeoGebra Internacional de Sáo Paulo, 3(2), p. 1 - 12, 2014c.

ALVES, F. R. V. Reconhecimento de padrões com o apoio do software GeoGebra: os casos da convergência pontual e uniforme. In: Revista TEAR, 2(2), p. 1 - 20. 2013.

ALVES, F. R. V. (2012). Insight: descrição e possibilidades no ensino do Cálculo. In: Vydia Educação, 32(2), 149 - 146.

ALVES, Francisco. R. V. Aplicações da Sequência Fedathi na promoção das categorias intuitivas do Cálculo a Várias Variáveis (tese de doutorado). Fortaleza: Universidade Federal do Ceará - UFC, 339f. 2011.

ALVES, Francisco. R. V. \& BORGES, Neto, H. Engenharia Didática para a exploração didática da tecnologia no ensino no caso da Regra de L'Hospital. In: Educação Matemática Pesquisa, 14(2), p. 337 - 367, 2012.

ALVES, Francisco. R. V; BORGES NETO, H. \& Alves Dias, M. Implicações e aplicações da Teoria dos Registros de Representação Semiótica no ensino do Cálculo. In: Jornal 
Internacional de Estudos em Educação Matemática, 5(1), p. $54-84,2012$.

ALMOULOUD, Ag Saddo. Fundamentos da Didática da Matemática. São Paulo: Editora UFPR, 2007.

ARSOVE, M. G. The Looman-Menchoff theorem and some subharmonic functions analoges. In: International Congress of Mathematicians. January, Washington, p. 94 - 105, 1954.

ARTIGUE, M. Modélisation et Reproductibilité en Didactiques de Mathématiques. In: Les Cahiers Rouge des Didactiques des Mathematiques, 8(1), p. 1 - 38, 1984.

ARTIGUE, M. Épistemologie et Didactiques, 1989.

ARTIGUE, M. Ingénierie Didactiques. Brun, J. (org.). In: Didactiques de Mathématiques, p. $243-264,1996$.

ARTIGUE, M. Didactical design in Mathematics Education. In: Carl Winslow (eds). NORMA08, Copenhaguen: Sense Publishers, Denmark, p. 7 - 16, 2009.

ARTIGUE, M. L'éducation mathématiques comme champ de recherché et champ de pratique: resultats et défis. EM TEIA: Revista de Educação Matemática e Tecnológica Iberoamericana, 3(3), p. 1 - 18, 2012.

ARTIGUE, M. L'impact curriculaire des Technologies sur L'Éducation Mathématiques. EM TEIA: Revista de Educação Matemática e Tecnológica Iberoamericana, 4(1), p. 1 - 15, 2013.

ÁVILA, G. O ensino de Cálculo e da Análise. In: Matemática Universitária, 33(1), p. 83-94, 2002.

BALACHEFF, N. \& GAUDIN, N. Students conceptions: an introduction to a formal characterization. Les Cahier du Laboratoire Leibniz. № 65, December, p. 1 - 25, 2002.

BOTTAZZINI, U. The Higher Calculus: a history of real and complex analysis from Euler to Weierstrass. New York: Springer-Verlag, 1986.

BOTTAZZINI, U. \& GRAY, J. Hidden Harmony - geometric fantasies: the rise of complex functions, New York: Springer-Verlag, 2013.
BROUSSEAU, G. Les obstacles épistemologiques et les problèmes en mathématiques. In: Revue Française de Pédagogie, INRP, 2(1), p. 101 116, 1976.

BROUSSEAU, G. L'observation des activités Didactiques. Revue Française de Pédagogie, INRP, 1(1), p. 130-140, 1978.

BROUSSEAU, G. Théorisation des phénomènes d'enseignement des Mathématiques (these de doctorat). Bourdeaux: Université Bourdeaux I, 905f. 1986a.

BROUSSEAU, G. Fondements et methodes de la Didactiques des Mathématiques. In: Recherche en Didactiques des Mathématiques. 7(2), p. 33 - 115, 1986b.

BROUSSEAU, G. Obstacle épistémologiques, conflit socio-cognitifs et ingénierie didactique. Canadá, Otawa: Édition CIRADE agence d'Arc, p. 277 - 285, 1986c.

BROUSSEAU, G. Le contrat didactique: le milieu. Recherche en Didactiques des Mathematiques, 9(2), p. 309 - 336, 1988.

BROUSSEAU, G. Les obstacles épistémologiques, problèmes et ingénierie didactique. G. In: Brousseau, (org.) Théorie des situations didactiques. Grenoble La Pensée Sauvage, p. 115 - 160, 1998.

BROUSSEAU, G. L'Émergence d'une science de la Didactique des Mathématiques. Repères IREM, 55(1), p. 19-34, 2004.

CECÍLIA, S. F. \& BERNADEZ, N. C. Introdução às funções de uma variável complexa. Rio de Janeiro: SBM, 2008.

CHAVEZ, E. Teaching Complex Numbers in High School. (dissertation in Natural Sciences). Louisiana: Louisiana State University. 66f. 2014.

CONWAY, J. B. Functions of One Complex Variable. Second Edition. New York: Springer Verlag, 1978.

CHEVALLARD. Y. La Transposition didactique. Paris: La Pensée Sauvage Édition, 1991.

DANENHOWER, P. Teaching and Learning Complex Analysis in at two British Columbia Universities. (doctoral thesis). Canadá: Simon Fraser University. 308f. 2000. 
DEBNATH, L. A brief history of the most remarkable numbers $\mathrm{e}, \mathrm{i}$ and $\gamma$ in mathematical sciences with applications. International Journal of Mathematical Education in Science and Technology. 46(6), March, p. 853 - 878, 2015.

DOUADY, Régine. Nacimiento y desarrollo de la didáctica de las matemáticas en Francia: rol de los IREM. In: Gomez, P. (org.) Ingenieria Didactica en Educación Matemática. Bogotá: Grupo Editorial Iberoamericano, p. 61 - 97, 1995.

DUVAL, Raymond. Sémiosis et Pensée Humaine: registres sémiotiques et apprentissages intellectuels, Editeur: Peter Lang, 1995.

FERGUSON, D. C. A theorem of Looman 0 Menchoff (thesis of Master in Arts). Quebec: McGill University, 1958.

FLANIGAN, F. J. Complex Variables: harmonic and analytic functions. California: San Diego State University, 1972.

GONG, S. Concise Complex Analysis. New Jersey: World Scientific, 2001.

GRAY, J. D. \& MORRIS, S. A. When is a Function that Satisfies the Cauchy-Riemann Equations Analytic? In: The American Mathematical Monthly, 85(4), April, p. 246 - 256, 1978.

GRAY, J. The real and complex: a history of Analysis in the $19^{\text {th }}$ Century, New York: Springer, 2015.

GREENE, R. O. \& KRANTZ, S. G. Function Theory of One Complex Variable. Third Edition, Graduate Studies In: Mathematics, no 40, Providence: American Mathematical Society, 2006.

HADAMARD, J. The psychology of invention in the Mathematical Field. Canada: Dover Press, 1945.

LIMA, E. L. Um curso de Análise. v. 1, Rio de Janeiro: SBM, 2010.

LABORDE, C. Affronter la complexité des situations didátiques d'apprentissage des mathématiques en classe: défis et tentatives. DIDASKALIA, 10(1), p. 97 - 112, 1997.
KRANTZ, S. G. Complex Analysis: the geometric view. New York: American Mathematical Society, 1990.

MARGOLINAS, C. Éléments pour l'analyse du rôle du maître: les phases de conclusion. In: Recherche en Didactiques des Mathématiques. 12(1), p. 113 - 158, 1992.

MARGOLINAS, C. D'evolution et institutionnalisation: deux aspects antagonistes du rôle du maître. Didactique des disciplines scientifiques et formation des enseignants, Paris: Maison Édition, p. 342347, 1995.

MARGOLINAS, C. Points de vues de l'élève et du professeur : essai de développement de la théorie des situations didactiques (Habilitation de recherche). Provence: Université de Provence. 160f. 2004.

NEEDHAM, T. Visual Complex Analysis. Oxford: Oxford University Press, 2000.

LINS NETO, A. Funções de uma variável complexa. Rio de Janeiro: SBM, 1993.

MEDVEDEV, F. Scenes from the History of Real Functions. Boston: Birkäuser-Verlag, 1991.

MARGOLINAS, C. Dévolution et intitutionnalisation: deux aspects antagonistes du rôles du maître. In: COMITI, C.; Bessot, M. P. Didactiques des disciplines scientifiques et formation des enseignants, $p$. $342-347,1995$.

PAP, E. Complex Analysis: through examples and exercises. London: Klumer Academic Publishers, 1999.

POLYA, G. \& LATTA, G. Complex Variables. Nova York: John Willey and Sons, 1974.

ROBERT, A. Ingénierie didactique sur les suites numériques après le baccalauréat. Les Cahiers Rouges des Didactiques de Mathématiques, p. $1-25,1984$.

ROBINET, J. De L'ingenierie Didactiques. Les Cahiers Blancs. 1(1), p. 1 - 11, 1983.

SHOKRANIAN, S. Uma introdução à Variável Complexa, Sao Paulo: Editora Moderna, 2011.

SCHWERDTFEGER, H. Geometry of Complex Numbers. Montreal: McGill University, 1979. 
SOARES, M. G. Cálculo em uma Variável Complexa. Rio de Janeiro: SBM, 2014.

SPIEGEL, M. R. et all. Complex Variables: with an introduction to a Conformal Mapping and its applications, New York: Schaum's Outlines Series. 2009.

TALL, D. Advanced Mathematical Thinking. London: Klumer Publishers, 1991.

TALL, D. From school to university: the effects of learning styles in the transition from elementary to advancedmathematical thinking. In: THOMAS, M. J. (eds.). Proceeding of the Seventh Annual Australian Bridging Network Mathematics Conference, Aucland: Aucland University, p. 9-26, 1997.

TIROSH, D. \& ALMOG, N. Conceptual adjustments in Progressing from Real and Complex Numbers. In: 13 th. Proceedings of Psychology of Mathematics Education, p. 221 - 227, 1989.

VERGNAUD, G. Quelques orientation théoriques eet methodoloiques des recherches française en Didactiques des Mathématiques. Recherche en Didactiques des Mathématiques. 2(2), p. 215 - 231, 1981.

WEGERT, E. Visual Complex Functions: an introduction with Phase Portraits, New York: Birkhäuser, 2012. 